Special issue in honor of Prof. H.K. Lichtenthaler

\title{
REVIEW
}

\section{Towards the quantitative and physically-based interpretation of solar-induced vegetation fluorescence retrieved from global imaging}

\author{
S. VAN WITTENBERGHE*,+ (D), N. SABATER ${ }^{* *}$ (D), M.P. CENDRERO-MATEO*(iD, C. TENJO*, \\ A. MONCHOLI*, L. ALONSO* (iD, and J. MORENO* \\ Laboratory for Earth Observation (LEO), Image Processing Laboratory (IPL), Parc Cientific, Universitat \\ de València, 46980 Paterna, València, Spain ${ }^{*}$ \\ Finnish Meteorological Institute, Erik Palménin aukio 1, 00560 Helsinki, Finland ${ }^{* *}$
}

\begin{abstract}
Due to emerging high spectral resolution, remote sensing techniques and ongoing developments to retrieve the spectrally resolved vegetation fluorescence spectrum from several scales, the light reactions of photosynthesis are receiving a boost of attention for the monitoring of the Earth's carbon balance. Sensor-retrieved vegetation fluorescence (from leaf, tower, airborne or satellite scale) originating from the excited antenna chlorophyll $a$ molecule has become a new quantitative biophysical vegetation parameter retrievable from space using global imaging techniques. However, to retrieve the actual quantum efficiencies, and hence a true photosynthetic status of the observed vegetation, all signal distortions must be accounted for, and a high-precision true vegetation reflectance must be resolved. ESA's upcoming Fluorescence Explorer aims to deliver such novel products thanks to technological and instrumental advances, and by sophisticated approaches that will enable a deeper understanding of the mechanics of energy transfer underlying the photosynthetic process in plant canopies and ecosystems.
\end{abstract}

Keywords: FLEX-Sentinel-3 tandem mission; fluorescence quantum efficiency; photosynthesis monitoring; quantitative remote sensing.

Fluorescence imaging: from the leaf to the global picture

Virtually all life on the Earth depends somehow on photosynthesis, the key process for fixing energy derived from harvested photons from sunlight and atmospheric $\mathrm{CO}_{2}$ for the eventual synthesis of organic material. The first step in this process implicates the photosynthetic light reactions that allow the use of the sun's light energy by photosynthetic organisms, capturing the photon energy by antenna pigments and converting it to excitation energy. Hence, the capability to monitor such critical light reaction processes, particularly by using imaging techniques at multiple scales, will substantially improve our capabilities to understand the spatial and temporal variability of the underlying processes, under variable climatic and environmental conditions.

Since the pioneering work of Hartmut Lichtenthaler and colleagues on imaging techniques at the leaf level (Lichtenthaler and Miehé 1997), the idea of using imaging techniques for more extended targets, from the canopy level to the ecosystem level and even at the global level, using potential satellite measurements, was identified as a fundamental research goal. While the techniques

\section{Highlights}

- FLEX mission combines fluorescence with more products to provide photosynthesis maps

- Focus on fluorescence quantum efficiency rather than fluorescence radiance retrievals

- Instantaneous photosynthesis maps will drive global GPP maps through data assimilation
Received 20 December 2020

Accepted 23 June 2021

Published online 20 July 2021

${ }^{+}$Corresponding author phone: (+34) 963544067

e-mail: Shari.Wittenberghe@uv.es

Conflict of interest: The authors declare that they have no conflict of interest. 
available at such time were not sophisticated enough for quantitative analysis and many aspects of the signal were not fully understood to allow accurate assessments, already in December 1998, the Fluorescence Explorer (FLEX) mission was proposed to the European Space Agency (ESA) as a potential Earth Explorer mission (Stoll et al. 1999). Initially conceived as a demonstration space mission, it was not selected, but the concept was considered of high scientific merit and recommended for further scientific and technical studies. Several preparatory activities were developed to address technical, observational, and scientific issues (Stoll et al. 2003). Hartmut Lichtenthaler and his team were involved in such activities, generalizing imaging techniques and the interpretability of the fluorescence signal in terms of photosynthetic activity (Lichtenthaler et al. 2005). After such studies and campaigns, in 2005, a full proposal for a dedicated mission to map vegetation fluorescence was again presented to ESA. Still named FLEX for historical reasons, the new concept was much more elaborated and technically mature (Moreno et al. 2006). The mission was then selected by ESA for successive phases and reshaped in 2010 to be converted into a tandem-mission concept flying together with Sentinel-3 to share data and optimize resources. The FLEX mission was finally selected for implementation in 2015 and currently is planned for a launch in 2024 (Moreno et al. 2016, Drusch et al. 2017). Since the initial work from the late 1990s, many developments on the passive monitoring of the fluorescence signal, regarding sensor technologies, instrumentation, retrieval methods, and signal interpretation have been driven by the studies promoted by the FLEX preparatory activities. During these decades, the FLEX mission has been a kind of umbrella for the realization of the pioneering ideas of Hartmut Lichtenthaler and colleagues.

The focus on the light-harvesting dynamics of photosynthesis from a remote basis for future global applications is now receiving a boost of attention generated by the demonstration of the retrieval of sun-induced vegetation fluorescence from several fields, airborne and even spaceborne sensors (Porcar-Castell et al. 2014, Rascher et al. 2015, Mohammed et al. 2019). The triggers for these advances are the improvements in very high spectral resolution imaging spectroscopy techniques. The Fluorescence Imaging System (FLORIS) imaging instrument on board FLEX will cover the wavelength range from 500 to $780 \mathrm{~nm}$ with a spectral sampling ranging from 0.1 to $2 \mathrm{~nm}$ and a spectral resolution of 0.3 within the $\mathrm{O}_{2}$ absorption bands and up to $3 \mathrm{~nm}$ within the full region (Coppo et al. 2017). These spectral characteristics will allow the disentanglement of the vegetation fluorescence (F) flux (often referred to as solar-induced fluorescence, or SIF) from the reflected radiance. The solar-induced vegetation fluorescence, emitted by the chlorophyll (Chl) $a$ molecule as a small radiative flux in the 650-850-nm range has hence become new quantitative information in the understanding of vegetation status from the leaf to the landscape and global scales. FLEX will cover the globe at a high spatial resolution of $300 \times 300 \mathrm{~m}$, measuring the vegetation $\mathrm{F}$ in Europe during morning hours, in tandem with Sentinel-3. Currently, equivalent or partly equivalent high-spectral resolution imaging and nonimaging sensors operate from towers, aircrafts, and satellites to pursue aspects of the F retrieval. Regarding satellite applications, in particular, those dedicated to atmospheric and trace gas studies, e.g., OCO-2 (Crisp et al. 2017), TANSO/GOSAT-

\footnotetext{
Abbreviations: A - absorbance; Chl $a$ - chlorophyll $a$; ${ }^{1} \mathrm{Chl} a^{*}-$ singlet excited Chl $a$; CFIS - chlorophyll fluorescence imaging spectrometer; DEM - digital elevation model; E - irradiance; ESA - European Space Agency; ESU - elementary sampling unit; ETR - electron transport rate; $\mathrm{F}$ - fluorescence flux; $\mathrm{F}_{680}$ - fluorescence flux retrieved at $680 \mathrm{~nm} ; \mathrm{F}_{760}$ - fluorescence flux retrieved at $740 \mathrm{~nm}$; FLD - Fraunhofer line depth; FLEX - fluorescence explorer; FLORIS - fluorescence imaging spectrometer; $F_{\max }-$ nadirmeasured maximum fluorescence flux; $\mathrm{F}_{\mathrm{s}}$ - steady-state fluorescence yield; FTS - Fourier transform spectrometer; FVC - fractional vegetation cover; $F_{v} / F_{m}$ - maximal quantum yield of PSII photochemistry; FWHM - full width at half maximum; GOME-2 - global ozone monitoring experiment-2; GOSAT - greenhouse gases observing satellite; GPP - gross primary productivity; HITRAN high-resolution transmission molecular absorption database; $i_{\mathrm{F}}-$ hemispherically integrated fluorescence; iFLD - improved Fraunhofer line depth method; $i_{\mathrm{L}}$ - hemispherically integrated incoming radiance or irradiance; $\mathrm{J}_{\mathrm{A}}$ - absorbed photon flux; $\mathrm{J}_{\mathrm{F}}-$ fluoresced photon flux; L - radiance; LAI - leaf area index; libRadtran - library for radiative transfer; $\mathrm{L}_{\max }$ - nadir-measured maximum spectral radiant flux received; MetOp - meteorological operational satellite program of Europe; MODTRAN - moderate resolution atmospheric transmission model; NIR - near-infrared; OCO-2 - orbiting carbon observatory-2; PAM - pulse-amplitude modulation; PSF - point spread function; R - reflectance; RC - reaction center; RTM - radiative transfer model; S5-P - sentinel-5 precursor; SFM - spectral fitting method; SpecFit - a spectral fitting method which retrieves the entire fluorescence spectrum; SRF - spectral response function; SZA - solar zenith angle; T - transmittance; TANSO - thermal and near-infrared sensor for carbon observation; TOC - top of canopy; TOA - top of atmosphere; TROPOMI - tropospheric monitoring instrument; UAV - unmanned aerial vehicle; VNIR - visible near-infrared; VZA - viewing zenith angle; $\mathrm{WV}$ - water vapour; $\alpha$ - (leaf) photon absorption factor; $\Phi_{\mathrm{CO} 2}$ - quantum efficiency of $\mathrm{CO}_{2}$ fixation; $\Phi_{\mathrm{F}}-$ fluorescence quantum efficiency.

Acknowledgements: SVW acknowledges her previous postdoctoral scholarship funded by the Generalitat Valenciana and co-funded by the European Social Fund (Grant no. APOSTD/2018/162) and her current funding by the 'Algorithm retrieval and product development study for the future Fluorescence Explorer/Sentinel-3 (FLEX-S3) tandem mission' project from the European Space Agency (ESA contract no. AO/1-8897/17/NL/MP). NS is funded by the Academy of Finland (postdoctoral AKA Grant agreement no. 324091) and MPCM is funded by the Ministry of Science and Innovation of the Spanish Government (Grant no. IJC/2018/038039/I). Further, we acknowledge the FLEXL3L4 project (advanced FLEX products) also funded by the Spanish Government (Project no. RTI2018-098651B-C51). SVW and MPCM also acknowledge the SENSECO network funded by the H2020 Framework Programme of the European Union (COST Action no. CA17134). Additionally, we thank Marco Celesti for his help with applying the SpecFit algorithm to the Q. ilex data in Fig. $6 \mathrm{C}$ and the anonymous reviewer suggesting thoughtful comments and edits.
} 
FTS (Glumb et al. 2014), GOME-2/MetOp (Munro et al. 2016), and TROPOMI/S5-P (Doornink et al. 2014), use sensors that partially overlap with the spectral range of interest to observe $\mathrm{F}$ at specific narrow spectral features. Recently, the use of the F measured at the canopy (Verma et al. 2017) and particularly at the satellite level (Sun et al. 2017, MacBean et al. 2018) has been observed as an interesting proxy for the estimation of gross primary productivity (GPP), based on its inherent link with photosynthesis. However, interpreting the retrieved fluorescence signal at any remotely observed scale, and additionally contextualizing it within the origin of the photosynthetic light reactions, is not a straightforward task. In order to improve the estimation of GPP from the future spaceborne missions as well as the currently retrieved $\mathrm{F}$ information, the primary requirements are the quantitative description of (1) the emission, accounting for all the photon losses along the path between the sites of emission and detection, and (2) the absorbed energy triggering this emission. Resolving these quantitative components will enable calculation of the actual quantum efficiency of the fluorescence emission process, an essential step to get to photosynthesis.

Therefore, this paper intends to bring a short overview of the effects contributing to the vegetation fluorescence signal captured or imaged by remote sensors, as well as the complementary information necessary to quantify and interpret that emission signal from a bottom-up approach, which is included in the FLEX mission plan. We start by describing the photosynthetic light absorption that triggers fluorescence emission at the level of the light-harvesting antenna within leaves, followed by the description of the effects that reduce and distort the emitted flux as it travels from leaves towards the remote sensor (e.g., on satellites) at varying spatial and temporal scales. We focus on the quantitative (i.e., amplitude-wise) and qualitative (i.e., shape-wise) aspects of the F flux spectrum determined from remote sensing imaging systems, and the need to overcome interfering physical effects in order to evaluate the light energy balance of the vegetation at the canopy and leaf scales. Finally, we point out the scientific opportunities provided by the upcoming FLEX mission, to carry a unique sensor payload to enable us to physically interpret SIF in the framework of the full canopy light reactions at the leaf level, which will deliver novel approaches to estimate photosynthesis and vegetation stress across landscapes.

\section{The photosynthetic light reactions, the gateway for carbon assimilation}

Light absorption, energy transfer, and energy fate: The total solar irradiance, i.e., the spatially and spectrally integrated radiant energy from the sun incident at the top of the Earth's atmosphere, averages 1,361 $\mathrm{W} \mathrm{m}^{-2}$ (Kopp and Lean 2011). On average, $45 \%$ of this incoming solar energy falls within the photosynthetic active radiation (PAR) spectral range $(380-710 \mathrm{~nm})$, the wavelength range which is utilized by the photosynthetic pigments (Fig. 1A). The main photosynthetic pigment photoreceptors, the chlorophylls, can absorb photons from all the wavelengths in the PAR range, with absorption maxima in the blue and red regions, due to the interaction between the electromagnetic radiation and their specific molecular structure. The Chl $a$ molecules are the most omnipresent photoreceptors in oxygenic photosynthesis which is seen as the result of both molecular constraints on the biochemical processes and the environmental pressure for adaptation during the Earth's history (Kiang et al. 2007). Moreover, Chl $a$ has polyvalent properties. While various Chls function as light-harvesting pigments, only $\mathrm{Chl} a-$ depending on its protein environment - functions either as a light harvester by electronic excitation trapping in the antenna or as a redox participant by electron-transporting events in the reaction centres (RC) of photosystems II and I (PSII, PSI) (Björn et al. 2009). The strong blue and red peaks in the spectral absorption profile of $\mathrm{Chl} a$ represent the two main electronic excited states of the molecule, but all PAR photons can bring the molecule to its constant singlet excited state $\left({ }^{1} \mathrm{Chl} a^{*}\right)$, which provides excitation energy partly directed to the RCs, and partly lost as a residual $\mathrm{F}$ emission. The chemical energy harvesting based on the final excitation energy reaching the RCs occurs in two complementary stages in plants, known as the Z-scheme with (1) an extraction of electrons from

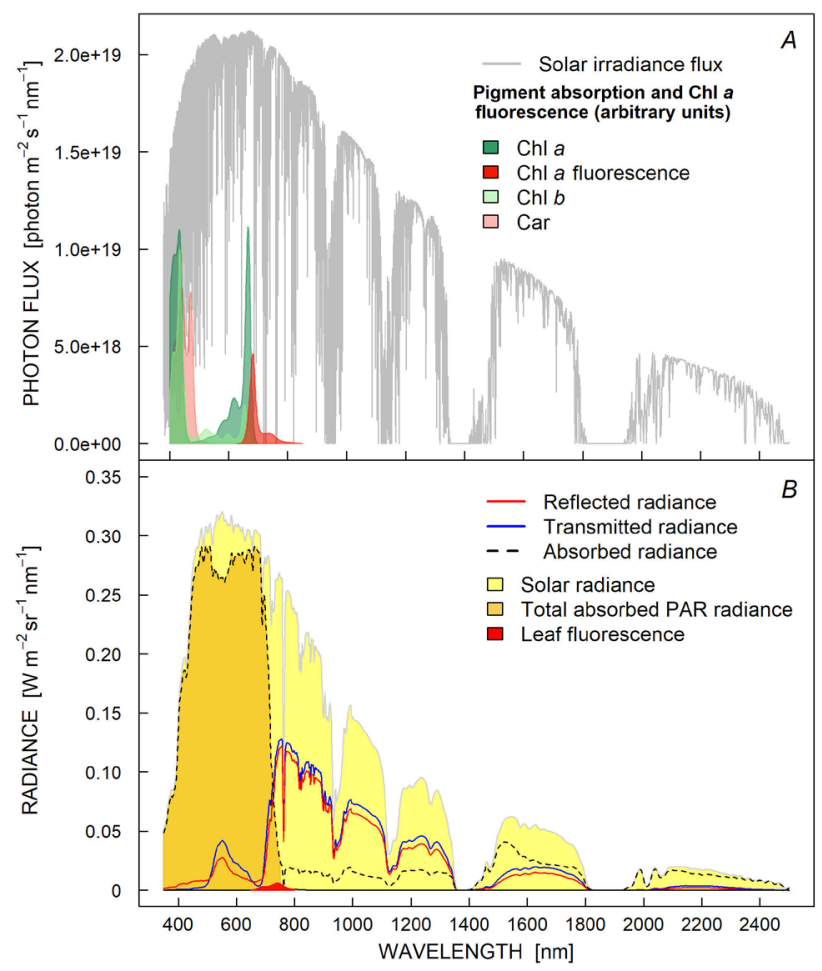

Fig. 1. (A) Full-range simulated solar photon flux (400-2,500 nm) with, for illustration purpose, the overlapping pigment absorption features in the photosynthetically active radiation range $(380-710 \mathrm{~nm})$ shown in arbitrary units. $(B)$ Example of reflected, transmitted, absorbed radiance measured from a Platanus $\times$ acerifolia leaf surface by a spectroradiometer with 1-nm sampling resolution, including the solar-induced leaf fluorescence $(650-800 \mathrm{~nm})$ measured using a leaf clip with the cut-off filter at $650 \mathrm{~nm}$. 
water using PSII, and (2) the reduction of the electron carrier $\mathrm{NADP}^{+}$using PSI (further used with ATP in the subsequent carbon reactions). The two photosystems working in sequence create an electron transport rate (ETR) across the antenna, providing flexibility to plants for efficient use of the captured light energy. While PSII has the largest antenna size, the smaller PSI antenna can provide alternative energy pathways such as the cyclic electron flow systems to regulate excessive energy (Shikanai 2007). Another important adaptive aspect of the antenna, thus providing functional robustness to the light-harvesting mechanism, is the role of energy losses (Krüger and van Grondelle 2017) that occur either (1) driven by the partial energy losses due to the unidirectional transfer from the light-harvesting pigments to the core RC-chlorophylls, or (2) caused by additional photoprotection pathways altering the fate of the excitation energy, with a prominent role of the xanthophylls (Bilger and Björkman 1990, Demmig-Adams 1990, Frank et al. 1999). The nonphotochemical quenching (NPQ) pathways involving reversible xanthophyll cycles are known to alter the complex link between the absorption of photons and the final harvesting of excitation energy and are further discussed in the following sections.

${ }^{1} \mathrm{Chl} a^{*}$ fluorescence emission as an indicator of the energy partitioning: The de-excitation of an excited ${ }^{1} \mathrm{Chl} a^{*}$ molecule within the complex antenna structure occurs by four main (not necessarily competitive) pathways: (1) nonradiative transfer of excitation energy to other chromophores, (2) controlled heat dissipation, (3) fluorescence emission, and (4) photochemistry in the case of the final RC-chlorophylls. As part of the result of the molecular de-excitation of ${ }^{1} \mathrm{Chl} a^{*}$ to the ground molecular state, $\mathrm{F}$ photons are released from the lowest vibration energy levels. At this molecular level, the shape or probability of the fluorescence emission occurs as the mirror-wise shape of the absorption from these lower molecular vibration levels (Fig. $1 \mathrm{~A}$ ), while the intensity or amplitude depends on the lifetime of the excited state. In other words, emitted $\mathrm{F}$ photons indicate the rate of energy de-excitation at the corresponding excited molecular lower level, and therefore serve as a good indicator of the excitation pressure on the Chl $a$ molecules. Laboratory techniques have exploited this information to obtain a measurable proxy for the light-harvesting state of the photosynthetic antenna, while passive remote sensing techniques capturing the emitted vegetation fluorescence are challenged to relate the SIF radiative flux to the lightharvesting and emission status of an underlying vegetation target at larger dimensions. This especially applies to the far-red SIF spaceborne retrievals that serve the main capability to date. However, in contrast to the active measuring systems for fluorescence in the lab, passive remote sensing techniques are not able to make use of a normalization approach based on a pulse difference method (i.e., pulse-amplitude modulation or PAM technique) to obtain a relative proxy of the emission status behaviour [e.g., by measuring pulse-induced steady-state $\left(\mathrm{F}_{\mathrm{s}}\right)$ or ratios such as $F_{v} / F_{m}$, based on alternating steady-state and saturating pulses]. Instead, the passive detection of vegetation fluorescence and its further meaningful relation with photosynthesis is forced to rely on the quantitative properties of the emission itself, combined with the information obtained from the associated reflectance and radiance signals.

The quenching process, or decrease of fluorescence due to changes in the energy partitioning, has been monitored both diurnally, daily (Amorós-López et al. 2006, Campbell et al. 2019), and seasonally (Campbell et al. 2019, Magney et al. 2019) with passive F or SIF techniques. The important role of the diurnal and seasonal evolutions of the violaxanthin-antheraxanthin-zeaxanthin (VAZ) xanthophyll pool, including their adaptations under intense drought and winter-sustained cold conditions (Demmig-Adams et al. 2020), remains an essential aspect to be studied in this regard. The immediate involvement of several xanthophylls as direct ${ }^{1} \mathrm{Chl} a^{*}$ fluorescence quenchers, explaining all high energy-dependent quenching $\left(\mathrm{q}_{\mathrm{E}}\right)$, was proposed in the 1990s using isolated chloroplasts (Gilmore and Yamamoto 1993). Meanwhile, also the lutein-epoxy-lutein cycle is investigated in parallel with the VAZ cycle, explaining an additional direct F quenching (Leuenberger et al. 2017). Nonphotochemical quenching of excitation energy becomes an even further complex matter when antenna structural changes or photoinhibition, in the sense of sustained downregulation of photosynthetic capacity and decreased number of functional $\mathrm{RCs}$, are also considered as actively regulated photoprotection processes (Lambrev et al. 2012). It is, therefore, also suggested that nonlinear relationships can be expected between relative fluorescence changes and this whole set of actual photoprotection mechanisms (Jahns and Holzwarth 2012), rendering fluorescence as a part of the information needed to resolve the energy partitioning.

\section{Reabsorption and scattering of the emitted $F$ through the leaf}

Linking 'true' molecular ${ }^{1} \mathrm{Chl} \boldsymbol{a}^{*} \mathrm{~F}$ to the apparent $\mathrm{F}$ emission: Even though nowadays it is possible to measure or image $\mathrm{F}$ emissions remotely and to follow its functional dynamics, the signal is a rather small radiance due to the overlap of strong pigments absorption with the $\mathrm{F}$ emission range (Fig. $1 B$ ), even at the closest distance possible from the leaf target. Lichtenthaler and colleagues introduced the term 'true' fluorescence referring to the molecular Chl $a$ fluorescence emitted by all Chl $a$ molecules within the antenna (Lichtenthaler et al. 1998) since it applies to the only quantitative measure that allows a general evaluation of the actual emission (and quenched) status of the photosynthetic apparatus in vivo. The exact spectral shape of the true fluorescence signal within the leaf is, however, difficult to measure due to several reasons. Fluoresced photons emerging from the ${ }^{1} \mathrm{Chl} a^{*}$ molecules need to travel through the leaf interior and even further if located in foliage within the canopy before reaching the sensor. After fluoresced photons from PSII (with a strong red peak $\sim 685 \mathrm{~nm}$ ) escape the molecule and the chloroplast, they are subjected to strong reabsorption 
in the red wavelength region before escaping the leaf surface. A second emission process via PSI occurs which is characterized by a broad far-red fluorescence emission and scattering of photons within the leaves and the canopy, affecting the probability of reaching an above-canopy sensor. As a result, leaf- and canopy-leaving fluoresced photons are affected by a wavelength-dependent probability of escape, both from the leaf (Agati et al. 1993, Gitelson et al. 1998) and from the outer canopy layer (Fournier et al. 2012, Yang and van der Tol 2018), before travelling through the atmosphere (Frankenberg and Berry 2018, Sabater et al. 2021) to be detected by remote sensors (see section 'Atmospheric effects on F estimates'). All these processes will not only affect the magnitude of the detected signal but also, to a large extent, modify its shape characteristics. To retrieve the quantitative information from the apparent $\mathrm{F}$ signal and relate it to the excitation pressure on the photosynthetic antenna, the next sections describe some steps to consider and properly interpret this information from remotely retrieved data.

\section{Accounting for the reabsorption (and reemission) of $F$} at the leaf level: From all expected $F$ photon interactions along the path between the emission sites and the detection site, the largest signal distortion effects - both quantitative and qualitative - take place inside the leaf medium due to the instant reabsorption by the same emitter (i.e., auto-absorption) and by the multiple interactions within the short path distances of other Chl $a$ molecules (Lichtenthaler et al. 1998, Buschmann 2007). As a result of these internal interactions, the shape distortions are smooth and driven by Chl $a$ as the main absorber of the emitted red light, primarily from PSII. In addition, more subtle underlying processes and molecular arrangements are known to affect the emission spectral shape, such as structural changes of the photosynthetic antenna related to the nonphotochemical quenching process (Miloslavina et al. 2008, Lambrev et al. 2010, Nematov et al. 2017) or the PSI-PSII antenna composition ratio (Franck et al. 2002, Pedrós et al. 2008). Leaf fluorescence spectral component analysis has indeed revealed, besides the strong reabsorption influences, minor subtle spectral shape influences assumed to be related to the structural nonphotochemical quenching behaviour (Magney et al. 2019). These subtle shape effects are again smooth and in accordance with in vitro observations of fluorescence shape modifications (Miloslavina et al. 2008, Lambrev et al. 2010). To account for the dominant reabsorption processes of fluoresced red photons due to Chl $a$, Gitelson et al. (1998) proposed a simple wavelength-dependent correction for leaf-emitted fluorescence whereby the spectrally resolved emission is divided by its overall escape probability or $[1-\mathrm{A}(\lambda)]$, with $\mathrm{A}[-]$ the wavelengthdependent absorbance at leaf level. To account for a higher degree of reabsorption, we suggest a simple escape probability correction applied for each leaf scattering surface (adaxial, abaxial) separately:

$i_{\mathrm{F}, \text { antenna Chl } a}(\lambda) \approx \frac{i_{\text {Fup, leaf }}(\lambda)}{\mathrm{R}(\lambda)}+\frac{i_{\text {Fdw, leaf }}(\lambda)}{\mathrm{T}(\lambda)}$ with the leaf radiative components $i_{\text {Fup }}$ and $i_{\mathrm{Fdw}}(\lambda)$ $\left[\mathrm{W} \mathrm{m}^{-2} \mathrm{~nm}^{-1}\right]$, respectively, the hemispherically integrated fluorescence emission in upward (adaxial) and downward (abaxial) direction, and $\mathrm{R}[-]$ and $\mathrm{T}[-]$ the wavelengthspecific reflectance and transmittance factors. The sum of both corrected terms provides the estimation of the total leaf emission, corrected for reabsorption effects (Fig. 2). For each leaf surface, the hemispherically integrated

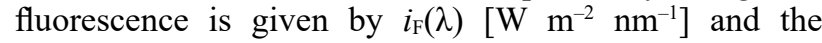
hemispherically integrated incoming radiance or irradiance at this surface point by $i_{\mathrm{L}}(\lambda)\left[\mathrm{W} \mathrm{m}^{-2} \mathrm{~nm}^{-1}\right]$. The leaf surface is here assumed a Lambertian emitter of fluorescence
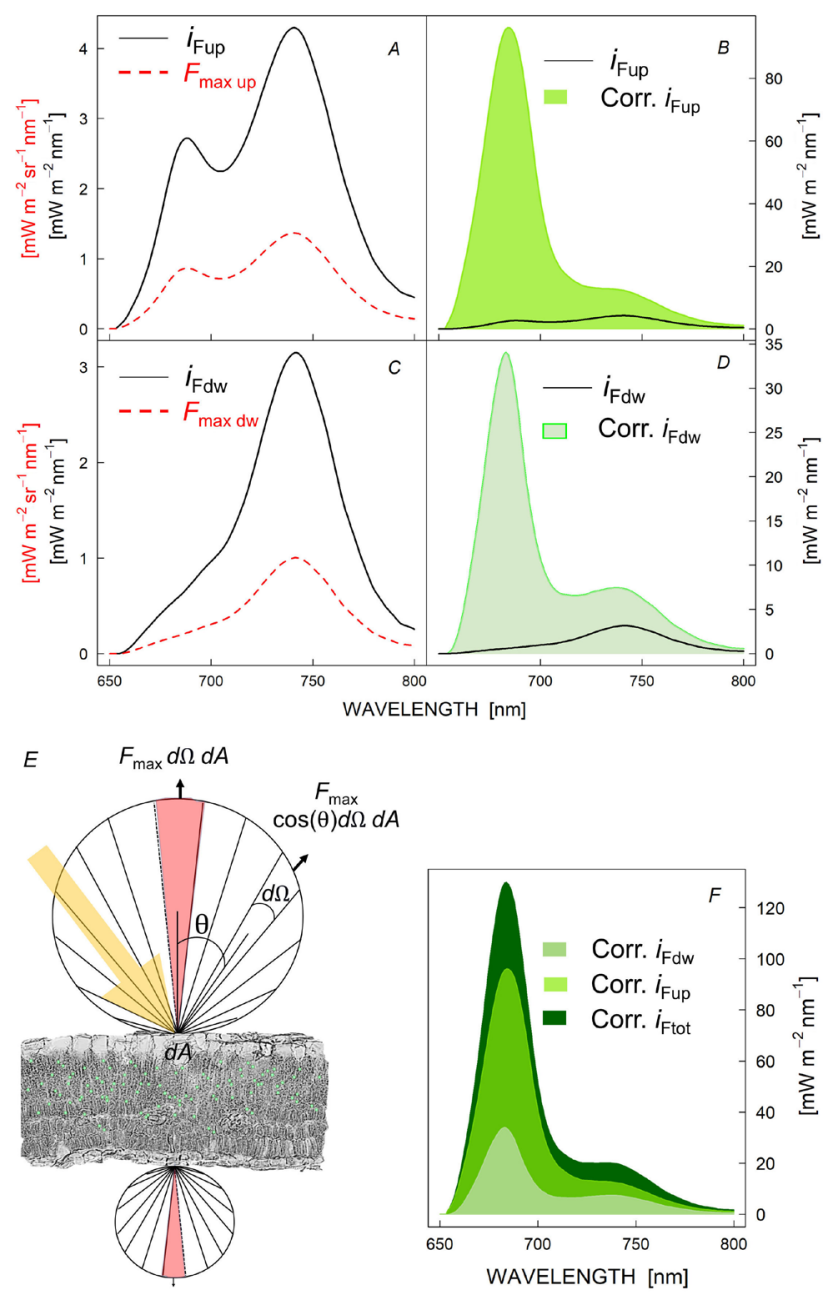

Fig. 2. Simple correction approaches to derive the true firstorder Chl $a$ fluorescence (labelled Corr. $\mathrm{i}_{\mathrm{Fup}}, \mathrm{i}_{\mathrm{Fdw}}$, or $\mathrm{i}_{\mathrm{Ftot}}$ ) from the spectroradiometric leaf fluorescence ( $i_{F u p}, i_{F d w}$ or $i_{\text {Ftot }}$ ) measured (using a 650-nm short-pass filter) from the adaxial $(A, B)$ and abaxial $(C, D)$ leaf surfaces. Here, the leaf is considered a Lambertian emitter of fluorescence photons with the maximal fluorescence signal per steradian emitted in the nadir direction $\left(\mathrm{F}_{\max }\left[\mathrm{W} \mathrm{m}^{-2} \mathrm{~nm}^{-1} \mathrm{sr}^{-1}\right]\right)(E)$. From the nadir-measured fluorescence, the hemispherically integrated $\mathrm{F}$ emission is calculated for both leaf sides and corrected for its escape probability $(1 / \mathrm{R}$ or $1 / \mathrm{T}$, respectively) to obtain the total emission $\left(\mathrm{i}_{\mathrm{Ftot}}\left[\mathrm{W} \mathrm{m} \mathrm{mm}^{-1}\right]\right)$ as the sum of both corrected components $(F)$. 
photons and for simplicity a Lambertian reflector/ transmitter of the incoming radiance L. By application of the cosine law for Lambertian surfaces to both nadirmeasured maximum fluorescence and incoming radiance vectors, $\mathrm{F}_{\max }$ and $\mathrm{L}_{\max }$, respectively, the hemispherical components are given as:

$$
\begin{aligned}
& i_{\mathrm{F}}(\lambda)\left[\mathrm{mW} \mathrm{m}^{-2} \mathrm{~nm}^{-1}\right]=\pi[\mathrm{sr}] \times \mathrm{F}_{\max }\left[\mathrm{mW} \mathrm{m}^{-2} \mathrm{sr}^{-1} \mathrm{~nm}^{-1}\right] \\
& i_{\mathrm{L}}(\lambda)\left[\mathrm{mW} \mathrm{m}^{-2} \mathrm{~nm}^{-1}\right]=\pi[\mathrm{sr}] \times \mathrm{L}_{\max }\left[\mathrm{mW} \mathrm{m}^{-2} \mathrm{sr}^{-1} \mathrm{~nm}^{-1}\right]
\end{aligned}
$$

where $\mathrm{L}_{\max }$ is the maximal spectral radiant flux received by the surface point, estimated from the reflected radiance of a white (Lambertian-behaving) reference surface. It has to be mentioned, however, that an additional effect also needs to be further accounted for when addressing the conversion of the apparent shape of the fluorescence spectrum back to the first-order original emission. The reabsorbed fraction of the original red emission will cause an additional second-order far-red reemission, contributing to a higher emission in the lower wavelengths. Therefore, this secondorder effect also needs to be taken into account to correctly retrieve the true first-order emission.

Applying Eqs. 1-3 to the leaf-emitted fluorescence, which can be measured using a 650 -nm short-pass filter, the apparent fluorescence shape-variable signal from different species (European nettle tree, Canary Island date palm, mulberry tree, and London plane) approaches the more uniform shape of a 'true' molecular Chl $a$ fluorescence emission for both emission surfaces (Fig. 3). The shape variation in apparent $F$ shape, largely driven by different Chl content (here: $16-101 \mu \mathrm{g} \mathrm{cm}$ ) as illustrated in Fig. $3 A, B$, indicates strong red $v s$. far-red peak ratio differences (Buschmann 2007, Van Wittenberghe et al. 2013). After correcting for the internal escape probability (Eq. 1) the shape differences largely disappear, and the emission shape renders a more representative of the firstorder molecular emission produced by the antenna Chl $a$ (Fig. $3 C$ ). Small shape differences are still noticeable when normalizing the shape to the overall emission (Fig. 3D) as would be expected, based on possible underlying effects of the antenna PSI-PSII composition and antenna-related structural effects.

PSI-PSII F contributions: Both PSII and PSI photosystems contribute to the total fluorescence emission, and their relative contributions and shape characteristics have been carefully studied in the lab for different temperatures and detergent solutions (Croce et al. 2000, Franck et al. 2002). Although it was originally thought that most of the emitted fluorescence emanates from PSII at room temperature, Roelofs et al. (1992) showed that the PSI contribution is around 5\% at $683 \mathrm{~nm}$ and around $30 \%$ at the far-red shoulder $(740 \mathrm{~nm})$. Based on selected room-temperature emission spectra from their native forms, Pedrós et al. (2008) showed how to model the in vivo emission spectrum as the sum of the PSI and PSII contributions, considering (1) the stoichiometry of the reaction centres, and (2) their difference in $\mathrm{F}$ lifetime. It is expected that plants acclimate to their given irradiance environments by two strategies: the adjustment of the PSII/PSI RC ratio and their antenna sizes (Chow et al. 1990). The general finding shows that shadow-adapted plants with large PSII antenna sizes have lower PSII/PSI ratios, in contrast to sun-acclimated plants with smaller PSII antenna sizes, which have a higher PSII/PSI ratio (Akoumianaki-Ioannidou et al. 2004). Using the approach of Pedrós et al. (2008), two cases are presented here, showing the normalized $\mathrm{F}$ emission spectrum of two antennas, i.e., respectively with a PSII/PSI ratio of 2.4 (Fig. 4A) and of 1.2 (Fig. 4B).

Towards the remote retrieval of fluorescence quantum efficiency: Despite the simple approach of correcting the apparent $\mathrm{F}$ emission from either one or both emission surfaces, the given correction method indicates a major loss of originally emitted photons, by a factor $50-60$ or

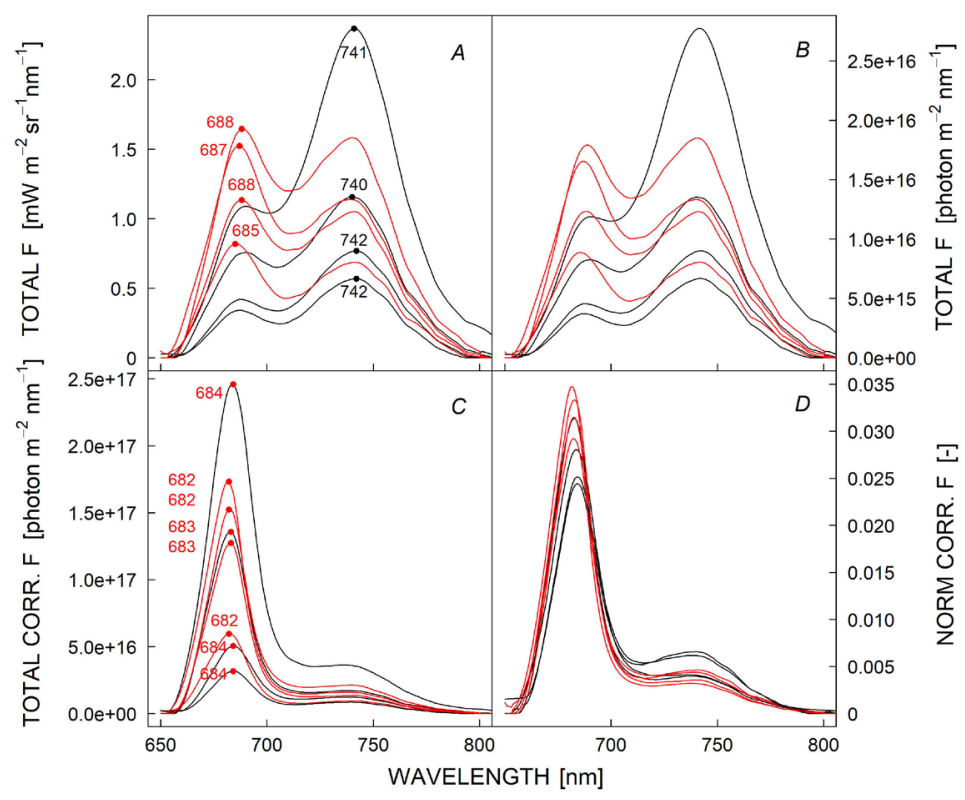

Fig. 3. Total nadir-measured leaf fluorescence emitted from different species (Celtis australis, Phoenix canariensis, Morus alba, Platanus $\times$ acerifolia) containing a range of various Chl contents $(16-101 \mu \mathrm{g}$ $\mathrm{cm}^{-2}$ ), expressed in radiance units $(A)$ and photon flux density units integrated over the hemisphere $(B)$. Peak maxima-associated wavelengths are indicated for leaves with higher apparent red emission (red) and apparent far-red emission (black) in panel A. After applying the correction for wavelength-dependent escape probability, the $\mathrm{F}$ shape is readjusted $(C)$, and all true emissions indicate a red peak maximum, indicated in red. To compare the shape differences between the samples, the emissions are normalized by their area in panel $D$. 


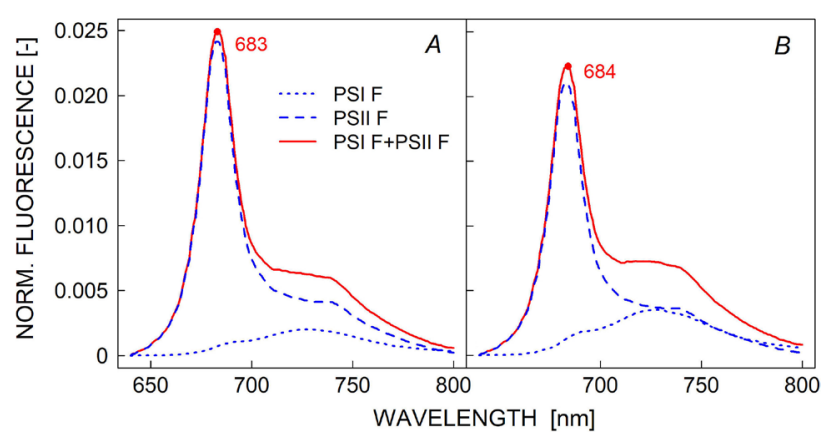

Fig. 4. Normalized elementary F spectrum for PSII/PSI values of $2.4(A)$ and $1.2(B)$, based on the method of Pedrós et al. (2008) using native PSI and PSII spectra of Croce et al. (2000) and Franck et al. (2002). The wavelength locations of the red peak maxima are indicated in red text.

higher in the case of red photons, that must be accounted for. Correcting this underestimation of emitted photons brings us one step closer to the quantitative interpretation of the $\mathrm{F}$ emission status of the antenna. Computing the fluorescence quantum efficiency $\left(\Phi_{\mathrm{F}}[-]\right)$ of the Chl $a$ molecules, expressing the fate of an absorbed photon to be eventually emitted as an $\mathrm{F}$ photon, requires the quantification of the number of absorbed photons triggering the emission. Hence, $\Phi_{\mathrm{F}}$ is a unitless parameter based on the ratio of the fluoresced to absorbed photon fluxes, expressed as $J_{\mathrm{F}}$ [photon $\mathrm{m}^{-2} \mathrm{~s}^{-1} \mathrm{~nm}^{-1}$ ] and $J_{\mathrm{A}}$ [photon $\mathrm{m}^{-2} \mathrm{~s}^{-1} \mathrm{~nm}^{-1}$ ] (Eq. 4A,B). To derive these quantum fluxes from the radiometric fluxes the following equations are applied:

$$
\begin{aligned}
\Phi_{\mathrm{F}, \text { antenna Chl } a}= & \frac{\text { number or flux of fluoresced photons }}{\text { number or flux of absorbed photons }}= \\
& =\frac{\int_{650}^{850} J_{\mathrm{F}}(\lambda) d \lambda}{\int_{400}^{700} J_{\mathrm{A}}(\lambda) d \lambda}= \\
& =\frac{1 /(h \times c) \int_{650}^{850} \lambda \times i_{\mathrm{Ftot}}(\lambda) d \lambda}{1 /(h \times c) \int_{400}^{700} \lambda \times \alpha(\lambda) \times i_{\mathrm{L}}(\lambda) d \lambda}
\end{aligned}
$$

whereby the quantum photon flux of fluoresced and absorbed photons is calculated from their respective radiometric quantities, with $h$ the Planck constant and $c$ the speed of light (Eq. 4C). Here, $\alpha$ [-] represents the wavelength-dependent absorption factor of incoming photons triggering the ${ }^{1} \mathrm{Chl} a^{*}$ excitation, often approximated by the overall leaf absorption factor in the PAR range or leaf fAPAR [-]. For classical applications, the leaf fAPAR or $\alpha$ has been often approximated by a single value of 0.84 based on the average absorption in the PAR range among many vascular plants (Björkman and Demmig 1987). Other spectrally detailed APAR calculations, i.e., based on the spectrally resolved fAPAR and the incoming PAR radiance, have been used to calculate wavelength-integrated radiometric absorbance fluxes. These APAR fluxes, calculated at the leaf level or through similar proxies at the canopy level, have been further used in combination with the leaf or canopy-emitted fluorescence radiometric flux to calculate the so-called apparent (spectral) fluorescence yield (Louis et al. 2006, Van Wittenberghe et al. 2015, Goulas et al. 2017). Such derived fluorescence quantum efficiency values typically indicate low range values of about $0.2-0.8 \%$ due to the underestimated (noncorrected, apparent) F emission on the one hand, and the overestimated total APAR flux assumed for the Chl $a$ excitation, on the other hand (both components are area-wise represented in Fig. $5 A$ ). We can assume that this large amount of absorbed solar energy, ultimately leading to the direct or indirect excitation of the Chl $a$ molecules, is considered a strong overestimation, since nonphotosynthetic absorbed fractions in the leaf or canopy surfaces are not accounted for. The amount of intercepted radiation triggering the $\mathrm{Chl} a$ molecules has remained difficult to retrieve, both at the leaf and canopy scales and has made it necessary to use proxies to retrieve the so-called 'green APAR' or 'APAR $\mathrm{Chl}_{\mathrm{Cl}}$, aiming to approximate the real photosynthetic APAR (Louis et al. 2005, Damm et al. 2010). Several strategies using vegetation green-related indicators (e.g., NDVI) as correction factors (Haboudane et al. 2004, Gitelson and Gamon 2015) or inversion of radiative transfer models (Zhang et al. 2014) have been suggested for the green APAR retrieval.

Here, high-spectral-resolution data provide novel opportunities. We illustrate here an estimation of the actual first-order absorption by Chl $a$ molecules based on the spectral shape of the absorbance and absorbed radiance. When multiplying the fitted $\mathrm{Chl} a$ pigment absorption spectrum with the incoming photon flux [photon $\mathrm{m}^{-2} \mathrm{~s}^{-1} \mathrm{~nm}^{-1}$ ] in the attempt to fit the specific photon absorption due to $\mathrm{Chl} a$, partially absorbed photon flux is retrieved (Fig. 5B). The apparent fluorescence quantum efficiency at leaf level $\left(\Phi_{\mathrm{F}, \text { leaf }}\right)$, when calculated by this approach, now attains values in the range of 3-5\%, which is in accordance with those reported by Pedrós et al. (2008). These authors stated that the $\Phi_{\mathrm{F}}$ at leaf level is typically in the range of a few percent $(2-5 \%)$, depending on the state of the leaf photosynthetic apparatus. Further correction of the apparent emission to account for the reabsorption effect brings us closer to the 'true' fluorescence quantum efficiency of the first-order reactions at the molecular scale. In this example, the ratio of both quantum fluxes provides a sensibly higher estimated $\Phi_{\mathrm{F}}$ in the order of $30 \%$ (Fig. 5C). In other words, the estimated molecular firstorder $\Phi_{\mathrm{F}}$ is one order of magnitude larger than the apparent leaf $\Phi_{\mathrm{F}}$ : 'true' $\Phi_{\mathrm{F} \text {, antenna Chl } a} \gg$ 'apparent' $\Phi_{\mathrm{F} \text {, leaf, where }}$ $\Phi_{\mathrm{F} \text {, antenna Chl a }}$ refers to the efficiency derived at the antenna Chl a molecules neglecting auto-absorption, and $\Phi_{\mathrm{F} \text {, leaf }}$ refers to the apparent efficiency, based on the emission affected by a photon loss due to auto- and a further degree reabsorption leading to an underestimated efficiency (Louis et al. 2005, Pedrós et al. 2010). Given these observations, it is shown that the true quantitative information of the $\mathrm{F}$ flux lies in further spectral processing, which will break 


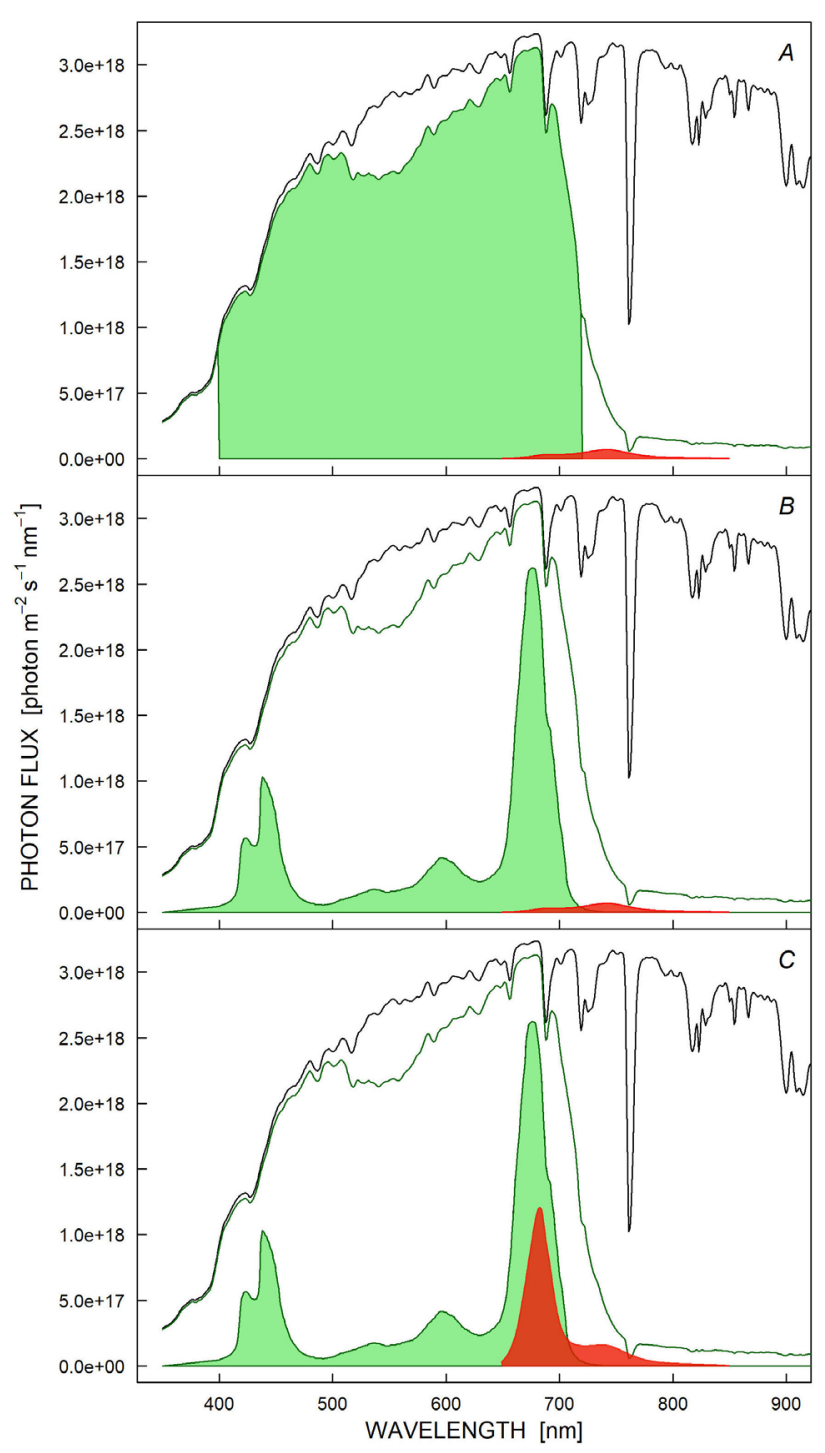

Fig. 5. Graphical representations of the derived absorbance (green) and emission (red) components to calculate the fluorescence quantum efficiency $\left(\Phi_{\mathrm{F}}\right)$, according to various assumptions: (A) all absorbed photons within 400-720 nm are exciting Chl $a$, resulting in a weak apparent $\mathrm{F}$ emission and the ratio of both components giving a $\Phi_{\mathrm{F}} \sim 0.7 \% ;(B)$ only photons directly absorbed by a first-order $\mathrm{Chl} a$ absorption lead to the apparent $\mathrm{F}$ emission and Chl $a$ is the main absorber of photons in the red edge region, resulting in apparent quantum efficiency of $\Phi_{\mathrm{F}} \sim 4 \%$; (C) an estimation of the true $\mathrm{F}$ emission is used, leading to an estimated 'true' quantum efficiency of $\Phi_{\mathrm{F}} \sim 30 \%$.

new ground for the understanding of photosynthetic lightharvesting from a remote sensing perspective.

\section{Further challenges for the quantitative assessment of $F$ at larger scales}

F retrieval methods: While fluorescence emissions may still be relatively easy to interpret at the leaf level where the full spectral emission can be directly measured, further challenges arise when (only scalar) $\mathrm{F}$ values are indirectly obtained from tower (Louis et al. 2005, Rossini et al. 2016), aircraft (Rascher et al. 2015, Tagliabue et al. 2020) or satellite platforms (Joiner et al. 2011, Guanter et al. 2014). The retrieval of vegetation fluorescence from these platforms relies on the capability of high-spectral resolution sensors (FWHM $<0.3 \mathrm{~nm}$ ) to resolve the solar or Earth's atmosphere absorption features, in particular, the solar Fraunhofer lines - Fe $(758.8 \mathrm{~nm})$ and KI $(770.1 \mathrm{~nm})$ or the Earth's telluric oxygen absorption bands $\mathrm{O}_{2}-\mathrm{B}(687.5 \mathrm{~nm})$ and $\mathrm{O}_{2}-\mathrm{A}(760.5 \mathrm{~nm})$ (Meroni et al. 2009). In contrast to $\mathrm{O}_{2}$-A-based retrievals, Fraunhoferbased resist atmospheric impacts but are noisier and more sensitive to assumed SIF spectral shape (Chang et al. 2020). On the one hand, there are fluorescence retrieval algorithms based on the Fraunhofer line depth (FLD) method (Plascyk 1975, Maier et al. 2004, Alonso et al. 2008) and the Spectral Fitting Method (SFM) (Meroni and Colombo 2006, Meroni et al. 2010). These methods retrieve only one scalar $\mathrm{F}$ value or $\mathrm{F}$ values for a small spectral window within each absorption feature, corresponding to the maximum absorption wavelength of the absorption feature, i.e., $\sim 687$ and $\sim 760 \mathrm{~nm}$ in the case of the oxygen bands. On the other hand, to resolve the entire spectrum of fluorescence flux, spectral fitting algorithms using wider spectral windows - such as the SpecFit algorithm (Cogliati et al. 2015, 2019) - can be applied to decouple the $\mathrm{F}$ and $\mathrm{R}$ signals over the entire emission range, by (1) modelling $\mathrm{R}$ and $\mathrm{F}$ with general mathematical functions, and (2) solving the nonlinear system of equations with a least-squares minimization method. Regarding the retrievalmethods implementation, twoimportantchallenges should be addressed by the fluorescence community: first, the standardization of the $\mathrm{O}_{2}-\mathrm{B}$ and $\mathrm{O}_{2}-\mathrm{A}$ spectral window intervals as well as the mathematical assumptions used for the different retrieval methods. Previous studies have shown that a non-optimum selection of the spectral window intervals could result in a $1-70 \%$ relative error in the retrieved fluorescence (Cendrero-Mateo et al. 2019), making the intercomparison of $F$ values between different studies challenging. Second, further work needs to be done to determine the retrieval methods' robustness and reliability (Morcillo-Pallarés 2020). In other words, errors are introduced in the retrieved $\mathrm{F}$ due to the mathematical assumptions from each type of retrieval method, as well as the correctness of the chosen interpolation method, and/or the implemented minimization method. The best way to reduce these errors is still under investigation and debate.

Canopy structure effects and scattering: Fluorescence retrieved at the TOC level is known to be affected by the characteristics of the canopy structure - i.e., leaf area index (LAI), leaf angle distribution, canopy gap fraction as well as by the illumination-target-sensor geometry, described by the solar and view zenith angles (SZA and VZA, respectively) and the relative azimuth angle (RAA) defined as the difference between sun and view azimuths (Verrelst et al. 2015, Pinto et al. 2017, van der Tol et al. 2019, Biriukova et al. 2020). The arrangement and orientation of the leaves modify the spectral composition, 
and spectral energy distribution of both the incoming and emitted radiation within the canopy (Pinto et al. 2017, van der Tol et al. 2019). Furthermore, the combined effects of canopy structure and the target-illumination geometry will define the sunlit $v s$. shaded canopy proportion, which will affect the absorbed energy flux and consequently the emitted $\mathrm{F}$ flux.

Overall, the top canopy layer effects are expected to drive the $\mathrm{F}$ emission. However, as just described, the $\mathrm{F}$ spectrum's magnitude and shape can be modified due to the structure-driven scattering and absorption effects. The chance of F photons escaping the canopy's top foliage layer is similar to that for reflected photons, and is affected by wavelength-dependent absorption, whereby red fluorescence has a lower chance of escaping the top canopy layer, while TOC far-red fluorescence is more easily transmitted and scattered. On this subject, different methods have been proposed for the compensation of the multiple scattering effects by modelling the scattering and absorption effects from the leaf (Agati et al. 1993) to the canopy scale (Hernández-Clemente et al. 2017, Romero et al. 2018, 2020; Liu et al. 2019, van der Tol et al. 2019, Yang et al. 2020).

Apart from the canopy structure itself, the VZA also plays a role in capturing the angular effects of the surface. For homogenous canopies, a maximal emission of fluorescence has been reported in the nadir direction and the backscatter direction of the solar principle plane (Pinto et al. 2017, Biriukova et al. 2020). Finally, the daily varying TOC irradiance levels, driven by the SZA, largely define the TOC irradiance and hence the magnitude of the emitted fluorescence (Du et al. 2017). With the highest solar elevation angles, more direct illumination reaches the TOC leaves, and the within canopy scattering effects are minimum. In contrast, during morning and afternoon hours the lower solar elevations allow a proportionally higher illumination of the lower leaves, increasing the scattering effect within the canopy and consequently the contribution of the bottom leaves to the total canopy fluorescence flux also increases (He et al. 2017, Yang and van der Tol 2018), particularly for discontinuous canopies.

For further applications, the vertical canopy incoming radiance profile, i.e., with decreasing light intensity as well as a different spectral composition needs further attention (Murchie and Horton 1997, Niinemets and Anten 2009). More work also needs to be done to properly account for the influence of the incoming radiance spectral composition and spectral energy distribution on the emitted F flux within the canopy (Moncholí et al. 2019). In this regard, the reflected radiance of the target may help to improve the analysis of the true incoming radiance, including the physical link with the specific absorbed energy wavelengths driving the emission (Fig. 5C).

Illustrative example: As an example of the potential quantitative and qualitative effects on $\mathrm{F}$ due to (1) retrieval methods and (2) canopy structural effects, Fig. 6 shows the simultaneous measurements of downwelling and upwelling irradiance as well as the retrieved fluorescence at leaf and TOC level of two canopies with a $100 \%$ vegetation cover but contrasting structures. The Quercus ilex (holm oak) canopy is characterized by plagiophile leaves, a high LAI but also a high canopy gap fraction. The Festuca spp. grass field is characterized by erectophile leaves, a low LAI but contrary to the $Q$. ilex canopy, a low canopy gap fraction. For both plant types, the leaf and TOC upwelling radiance,
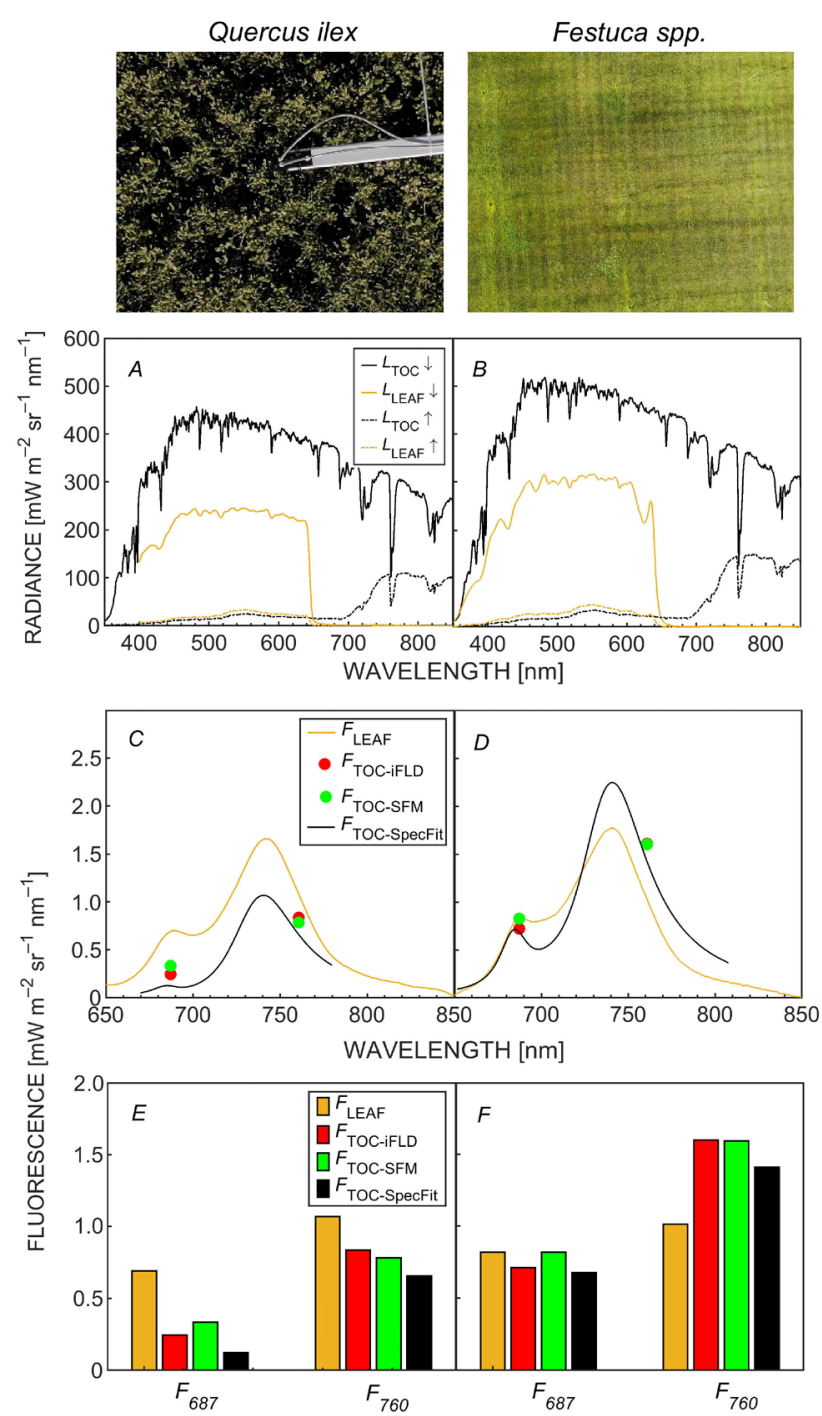

Fig. 6. Two vegetation types are compared, the oak crown (Quercus ilex) vs. a grass (Festuca spp.) canopy, shown from nadir views in the top row. Panels $A, B$ show the top of the canopy (TOC, black lines) and leaf (orange lines) radiometric measurements of downwelling ( $\mathrm{L} \downarrow$, solid line) and upwelling (L个, dashed line) radiances. The corresponding TOC radiative fluorescence flux retrieved with the FloX system with three retrieval methods are shown $(C, D)$ : iFLD (red bullets), SFM (green bullets), and SpecFit (black line) along with direct leaf fluorescence $\left(\mathrm{F}_{\mathrm{LEAF}}\right)$ measurements acquired with the FluoWat leaf clip (orange line). Panels E,F compare for each species the retrieved red $\left(\mathrm{F}_{687}\right)$ and far-red fluorescence $\left(\mathrm{F}_{760}\right)$ at the leaf (orange) and canopy level (iFLD - red, SFM - green, SpecFit black). The canopy measurements took place, respectively, at 2 and $3 \mathrm{~m}$ above the canopy. 
being the sum of reflected-and-emitted radiances, show similar shapes and magnitudes within the visible region of the spectrum (400-650 nm; Fig. 6A,B). Both fluxes were measured simultaneously but under slightly different solar irradiance conditions due to the use of the FluoWat leaf clip (Alonso and Moreno 2010) and the FloX system (FLuorescence boX, JB Hyperspectral Devices UG, Düsseldorf, Germany) for leaf and TOC measurements, respectively. For both measurement scales, Fig. $6 C, D$ compares the obtained fluorescence results, i.e., at the leaf (orange line $-\mathrm{F}_{\mathrm{LEAF}}$ ) and TOC level according to various retrieval algorithms (red bullet - iFLD, green bullet SFM, and black line - SpecFit). Interestingly, in contrast to Festuca spp., the canopy $\mathrm{F}$ emission flux from $Q$. ilex is noticeably reduced concerning the leaf emitted flux (the latter, moreover, measured under a lower incoming radiance). Additionally, the proportion of red and far-red emission between the leaf and canopy fluxes of the two canopies is different. The $Q$. ilex canopy red $\mathrm{F}$ is $1-4$ times lower than the leaf emitted red F; while Festuca spp. red $\mathrm{F}$ is only $0.1-0.2$ times lower than the leaf level $\mathrm{F}$ flux. A decreased leaf-to-canopy $\mathrm{F}$ emission flux for $Q$. ilex can be argued based on its lower sunlit fraction, with $\mathrm{F}$ emission decreasing in parallel. On the other hand, the Festuca spp. canopy F mainly originates from the TOC leaves which are overall more directly sunlit, resulting in a more similar emission flux between the leaf and canopy surface. These observations point out that a higher canopy gap fraction together with a given leaf angle distribution may lead to a nonhomogeneous and lowered light interception, and eventually a lowered global fluorescence emission flux. Finally, Fig. $6 E, F$ shows the red $\left(\mathrm{F}_{687}\right)$ and far-red $\left(\mathrm{F}_{760}\right)$ fluorescence emissions measured or estimated with different retrieval methods. When comparing TOC results, a discrepancy among the methods is observed, i.e., both $\mathrm{F}_{687}$ and $\mathrm{F}_{760}$ SpecFit retrievals present lower values than those obtained from the iFLD and SFM retrievals methods, which focus on the exploitation of a particular absorption band (i.e., $\mathrm{O}_{2}-\mathrm{A}$ and $\mathrm{O}_{2}$-B). These results corroborate the effect of using distinct spectral intervals and mathematical assumptions in the final retrieved $\mathrm{F}$ value, making the standardization of the retrieval methods' implementation a crucial step toward the development of a solid validation strategy.

Fractional vegetation cover: Imaging at larger spatial scales or over scenes with a less than $100 \%$ fractional vegetation cover (FVC) will include the contributions of nonfluorescent targets (e.g., soil, branches) to the pixel radiometric signal. As in most applications, knowing the FVC specific to healthy photosynthetic green vegetation is required for the interpretation of the retrieved fluorescence. The photosynthetic surface layer or green FVC is an estimate of the surface photosynthetic fractional cover, which is affected by clumping or discontinuity in the canopy cover (with increasing branch portions) and/or any soil radiative contribution within the pixel. Commonly, retrieval methods of green FVC are based on empirical or physical models or machine learning methods (Liang and Wang 2020). To illustrate how the green FVC (the sum of the visible sunlit and shaded canopy fractions) and the nonvegetated cover affect the fluorescence flux at a pixel level, a simplified 1D canopy simulation of canopies using reflectance factors to present soil, as well as sunlit and shaded vegetation contributions in different ratios under clear skies is shown in Fig. 7. By using fixed input reflectance and $\mathrm{F}$ emission spectra related to only two physiological emission states of leaves, the resulting fluorescence flux at the pixel level indicates the high contribution of the sunlit fraction, with only a minor contribution from the shaded canopy fraction. The simulation does not account for additional scattering effects between additional leaf layers and assumes the sunlit fraction of a single TOC layer as the main contributor to the canopy-leaving fluorescence flux. This simplified approach demonstrates, however, the dominating physical link between the pixel's reflected radiance originating from the sunlit TOC and the corresponding fluorescence emission flux for the three pixels $(\mathrm{a}, \mathrm{b}, \mathrm{c})$ used here as an example. Both components, the pixel's reflected radiance, and its fluorescence emission are needed to resolve the $\Phi_{\mathrm{F}}$ of the photosynthetic surface. Further accounting for the vertical variability beyond the TOC signal will require additional canopy models (Niinemets and Anten 2009). Generation of more realistic (possibly 3D) vegetated scenes based on RTM vegetation (van der Tol et al. 2009, Gastellu-Etchegorry et al. 2012, Hernández-Clemente et al. 2017) can further contribute to the simulation of more complex landscape images (including the DEM and land cover types). These types of studies will help to elucidate the surface radiation budget and the sensitivity of the various instrument response functions to the surface heterogeneity, and their effects on the retrieved fluorescence (Vicent et al. 2016, Tenjo et al. 2018).

\section{Challenges for global $F$ estimates: analysing atmospheric effects and imaging sensor requirements}

Atmospheric effects on F estimates: The spectral shape of the emitted $\mathrm{F}$ signal is also modified as it passes upwards through the atmosphere within a canopy, and from there to remote sensors placed either on towers (Daumard et al. 2010, Sabater et al. 2018), aircraft (Siegmann et al. 2019), or satellites (Frankenberg and Berry 2018). At specific wavelengths in the spectral range overlapping where $\mathrm{F}$ is emitted, atmospheric constituents of water $\left(\mathrm{H}_{2} \mathrm{O}\right)$ and oxygen $\left(\mathrm{O}_{2}\right)$ strongly absorb the fluorescence emitted photons resulting in a signal that is no longer spectrally smooth. Besides these effects, other atmospheric constituents such as aerosols also modify the spectral shape of the emitted $\mathrm{F}$, although not leading to abrupt transitions (see Fig. 8). For a detailed review of those atmospheric effects impacting the spectral interval see Sabater et al. (2021).

Light interactions in the atmosphere are far from being simple. Atmospheric gases and aerosols absorb and scatter light in different ways. Regarding molecular absorption, a distinct characteristic spacing between energy levels (and hence the wavelength of absorption/emission) is associated with the different types of excitations or transi- 
FRACTION SOIL/SUNLIT VEG./SHADED VEG.

\begin{tabular}{|c|c|c|c|}
\hline $1 /$ & $0.8 /$ & $0.6 /$ & $0.5 /$ \\
$0 /$ & $0.2 /$ & $0.2 /$ & $0.3 /$ \\
0 & 0 & 0.2 & 0.2 \\
\hline $0.5 /$ & $0.3 /$ & $0.3 /$ & $0.2 /$ \\
$0.4 /$ & $0.4 /$ & $0.5 /$ & $0.6 /$ \\
0.3 & 0.3 & 0.2 & 0.2 \\
\hline $0.2 /$ & $0.1 /$ & $0.1 /$ & $0 /$ \\
$0.7 /$ & $0.7 /$ & $0.8 /$ & $1 /$ \\
0.1 & 0.2 & 0.1 & 0 \\
\hline
\end{tabular}

SPECTRALIY INTEGRATED FLUORESCENCE

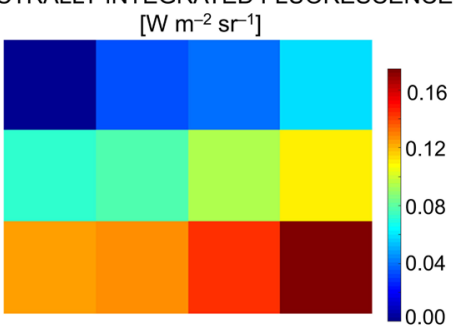

PIXEL EXAMPLES

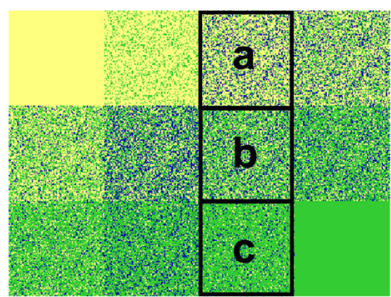

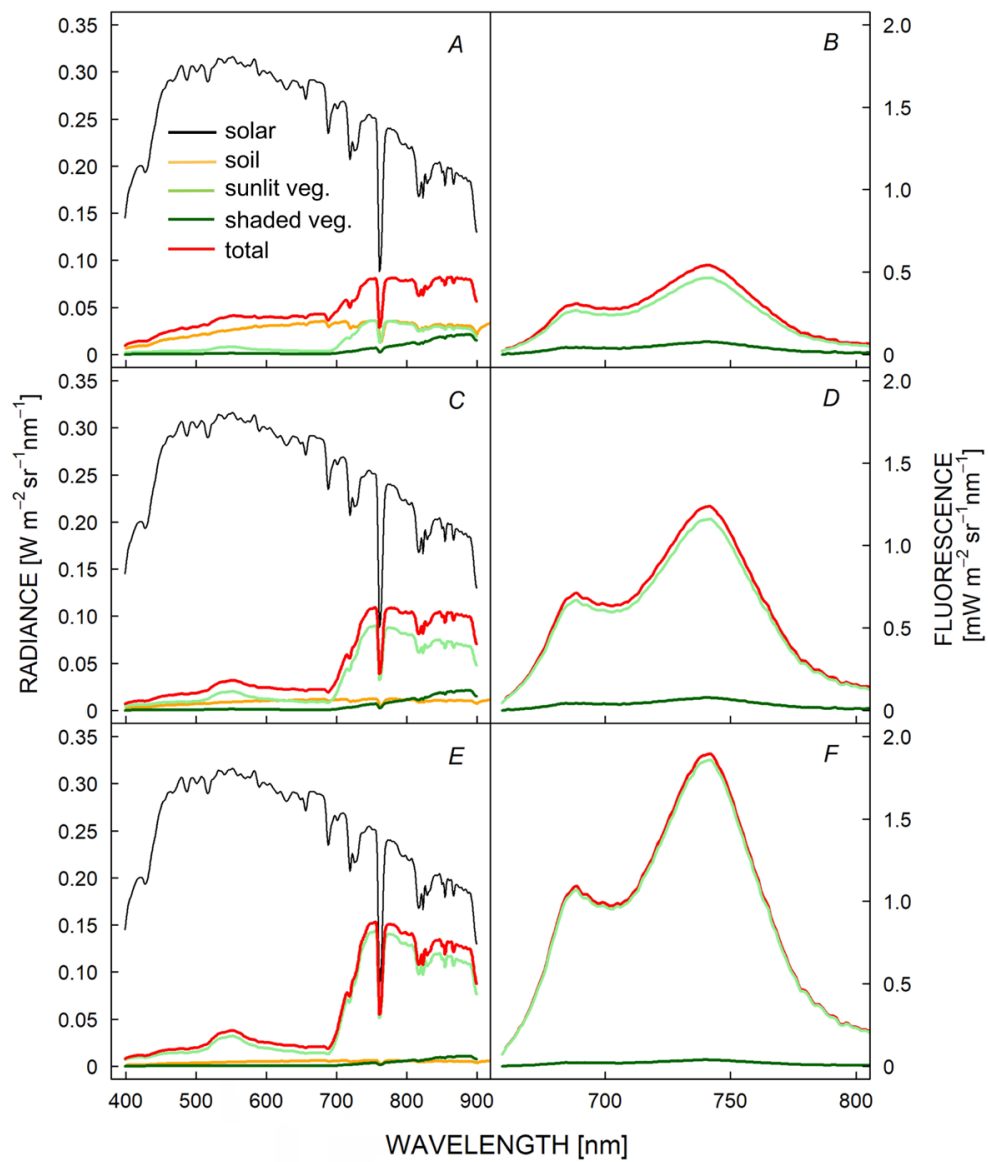

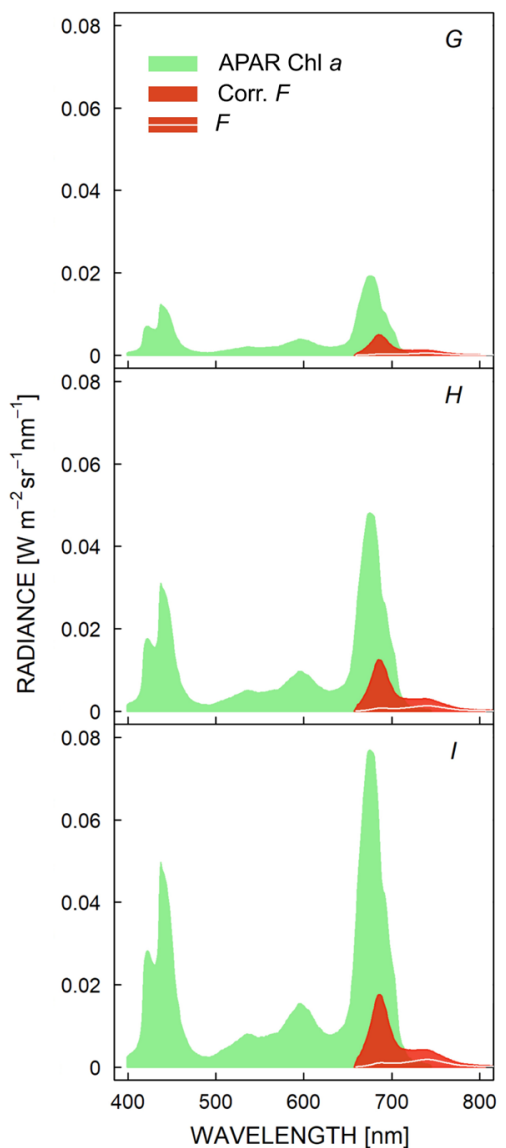

Fig. 7. Simulated 2D example of the heterogeneous fractional cover effects of a field maple (Acer campestre) canopy, considering the soil and sunlit and shaded vegetation components (upper row), based on input spectra of field maple for reflectance and fluorescence emitted under direct and filtered (neutral-density) solar irradiance to simulate the shade effects. The spectrally integrated fluorescence at each pixel is shown in the upper row middle figure; for three selected pixels (labelled $\mathrm{a}$ - low fluorescence emission; $\mathrm{b}$ - medium emission; and $\mathrm{c}$ - high emission) the radiance components in the optical domain $(A, C, E)$, the fluorescence contributions of sunlit and shaded areas (pixel a - panel $B$; pixel $\mathrm{b}$ - panel $D$; pixel $\mathrm{c}$ - panel $F$ ), and an estimated retrieval of corrected $\mathrm{F}(\mathrm{Corr}$. F) and APAR Chl $a$ are shown $(G, H, I)$.

tions, whether electronic or due to vibration or rotation. The resulting large number of possible vibration-rotation transitions is, in essence, what leads to the complexity in the molecular spectra observed (Petty 2006). Because the rotational energy levels are not equally spaced in the energy domain, and not all molecules start at the same energy level, molecules can present absorption bands with many transitions within relatively narrow spectral intervals. This is the case of the water vapor (WV) absorption bands present in the near-infrared (NIR) (see Fig. 8, blue line). $\mathrm{WV}$, and more precisely, the integrated value of the WV content in the atmospheric column, is a relatively accurate atmospheric variable that can be estimated through satellite remote sensing techniques (see some validation results in Fischer et al. 2010, Diedrich et al. 2015). However, its concentration varies quite dynamically since $\mathrm{H}_{2} \mathrm{O}$ is involved in many atmospheric chemical reactions as well as in the formation of aerosols and clouds (Naumann and 


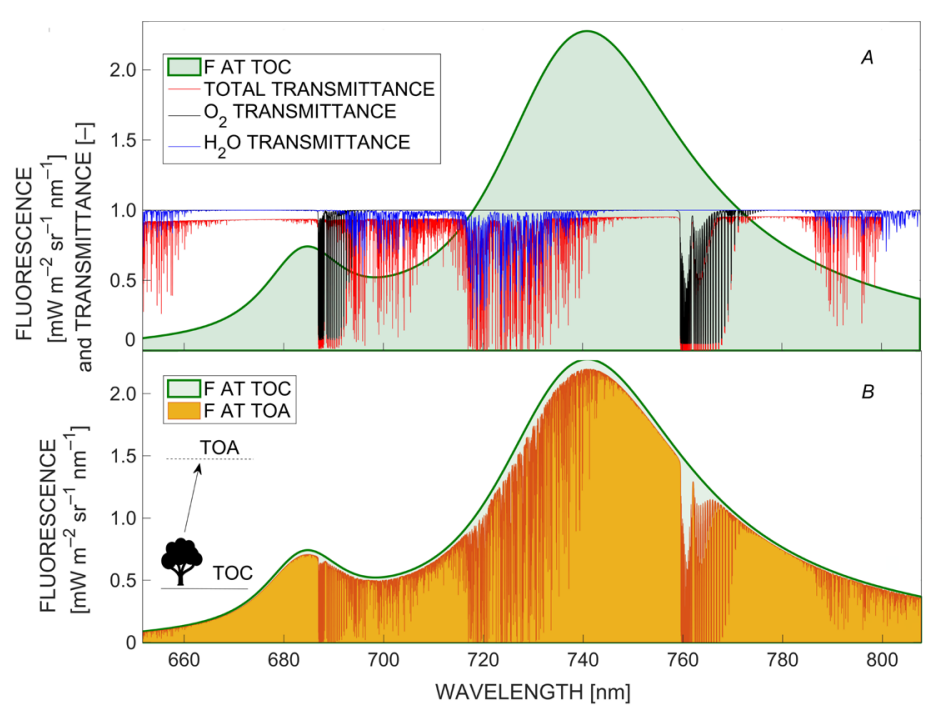

Fig. 8. (A) F at TOC of a Festuca spp. canopy (green area), along with total atmospheric transmittance (red), $\mathrm{O}_{2}$ transmittance (black), $\mathrm{H}_{2} \mathrm{O}$ transmittance (blue). (B) F at TOC (green curve area) overlapped with the F signal propagated at TOA level (orange area); the edge colour in dark orange emphasizes to appreciate of the fine absorption atmospheric features.
Kiemle 2020), which also drive atmospheric motions through radiative and nonradiative (convection and condensation) transport from the Earth's surface. This fact implies that a consistent and simultaneous measurement of the water vapor content in the atmospheric column would be required to accurately estimate the spectrally resolved $F$ signal in the red-edge region.

Oxygen, a well-mixed atmospheric gas, has been extensively used in atmospheric remote sensing for over half a century to determine surface pressure, cloud top heights, and aerosol properties, or as part of some trace gases processing algorithms (Long and Hodges 2012). The oxygen mixing ratio is quite stable and uniformly distributed in the atmosphere. However, as for any other gas, energy transitions do not simply occur at discrete wavelengths because of line broadening effects that in the atmosphere are dominated by collision (pressure) broadening and Doppler broadening; the first is due to the collisions between 'air' molecules and emitting/ absorbing molecules, and the second is due to the relative motion of absorbing/emitting molecules. As in any other gas, temperature and pressure conditions also modulate the final molecule density profile, therefore, triggering changes in the absorption regions. These aspects are relatively well-known, and their effects are included in most of the atmospheric radiative transfer models, e.g., libRadtran (Emde et al. 2016), MODTRAN (Berk et al. 2005), which generally contain detailed information regarding the absorption line-by-line parameters of the most abundant atmospheric gases and their dependency on the temperature and pressure conditions, for instance, by including information from the HITRAN molecular spectral database (Hill et al. 2016).

In the absorption regions, besides the accurate modelling of the absorption effects, the importance also lies in the precise modelling of aerosol and gaseous scattering effects. Aerosol and gas scattering can enlarge or shorten the upwelling photon's path, thus modifying the final radiance acquired at the sensor level. Therefore, these regions become more sensitive to changes in the aerosol vertical profile than those spectral intervals not affected by absorption features (Vicent et al. 2017, Sabater et al. 2021). Additionally, similar reasoning applies to other soconsidered minor sources, such as the contribution of the inelastic Raman scattering, that can significantly impact the radiance signal within the absorption features producing an artificial filling-in effect (Vasilkov et al. 2013).

Nonetheless, besides the complexity involved in the solar light interactions within the absorption regions, whether telluric or solar, these regions provide advantageous spectral intervals for the measurement of $\mathrm{F}$. At the TOA level within these absorption features, the fraction of the $\mathrm{F}$ signal versus the total acquired radiance signal increases significantly (Fig. 8).

Fig. $9 A$ shows a radiance spectrum at the TOA level (black line) after being reflected from a vegetation target and propagated through the atmosphere. At high spectral resolution, numerous absorption lines can be distinguished covering the entire $\mathrm{F}$ emission range. Fig. $9 B$ shows the fraction, in percent, between the $\mathrm{F}$ and the total radiance signal $\left(\mathrm{L}_{\mathrm{TOA}}\right)$ at the TOA level. Interpreting this fraction $\left(\mathrm{F} / \mathrm{L}_{\mathrm{TOA}}\right)$ as a kind of signal-to-noise ratio concept, it is easily observed that the potential to measure the subtle F signal increases when exploiting the absorption features. In this panel, absorption line regions originated within the terrestrial atmosphere, mainly for $\mathrm{H}_{2} \mathrm{O}$ and $\mathrm{O}_{2}$, are plotted over the $\mathrm{F} / \mathrm{L}_{\mathrm{TOA}}$ signal together with their corresponding transmittance spectra for visualization purposes. Also, fine solar absorption lines are spread across the full $\mathrm{F}$ emission range, sometimes overlapping with the terrestrial absorption features. In this figure, regions, where the solar Fraunhofer lines do not overlap with main telluric gas absorptions, are labelled.

Thus, given the higher sensitivity to detect fluorescence in absorption features, various retrieval techniques have been developed in the last years focusing either on the exploitation of distinct, particular solar lines or broader spectral telluric absorption regions (see examples referenced in Frankenberg and Berry 2018). The exploitation of either solar or telluric absorption lines has distinct 


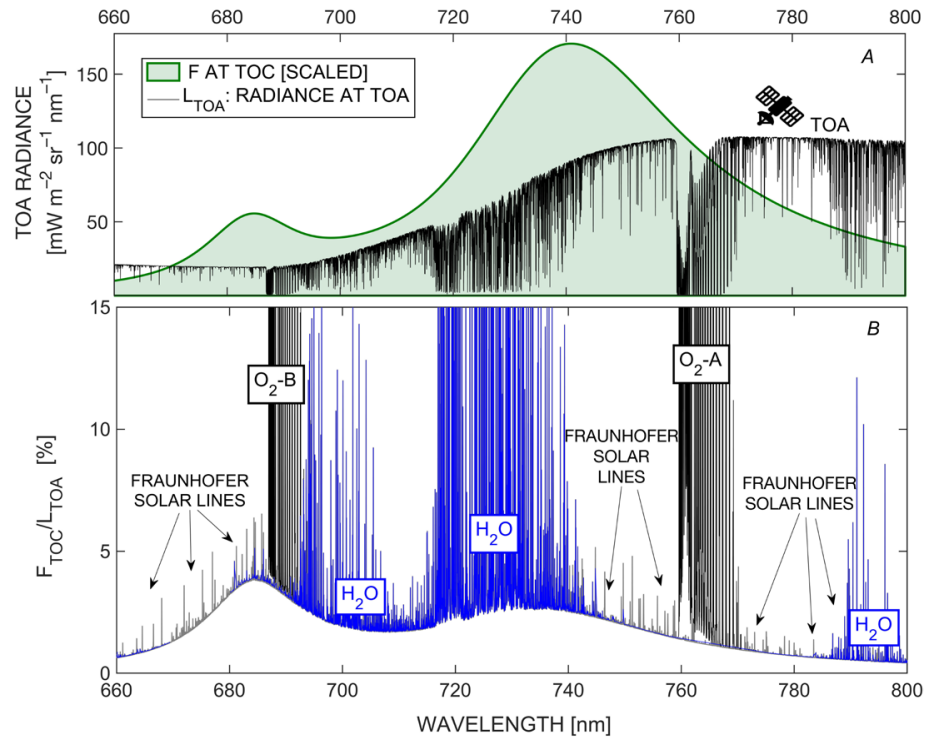

Fig. 9. (A) Scaled F at TOC of a Festuca spp. canopy (green area), along with top of atmosphere (TOA) radiance spectrum $\left(\mathrm{L}_{\mathrm{TOA}}\right)$ reflected from a vegetation target and propagated through the atmosphere (black line). (B) Fraction of $\mathrm{F} / \mathrm{L}_{\mathrm{TOA}}$ in percent (green curve line), along with $\mathrm{O}_{2}$ and $\mathrm{H}_{2} \mathrm{O}$ transmittances (black and blue lines, respectively). Spectral intervals where Fraunhofer solar is not overlapped with $\mathrm{O}_{2}$ or $\mathrm{H}_{2} \mathrm{O}$ are highlighted in yellow. Details about the atmospheric simulation: Mid-latitude summer model of the atmosphere, a target set at the sea level, nadir viewing, solar zenith angle of 20 degrees, and an aerosol optical thickness of $0.10[-]$. advantages and disadvantages. In brief, the use of the solar lines allows the simplification of the atmospheric modelling at the expense of working with narrower absorption lines requiring highly demanding instrument calibration accuracy and statistically-based retrieval methods, such as the singular value decomposition (SVD) method (e.g., Guanter et al. 2012, Frankenberg et al. 2014, Chang et al. 2020). In contrast, $\mathrm{F}$ is more easily detected in the broader main telluric absorption regions, particularly in $\mathrm{O}_{2}$ regions; therefore, relaxing the demanding instrument requirements but requiring a highly accurate atmospheric characterization.

Note that the debate of whether to use either solar or telluric regions blurs when aiming to estimate spectrally resolved $\mathrm{F}$, where no matter what, atmospheric effects need to be accounted for. In this respect, current atmospheric chemistry-focused satellites provide $\mathrm{F}$ estimates exclusively at certain narrow spectral intervals [see Table 3 of Mohammed et al. (2019) for a review of current satellite F-measuring capabilities]. The estimation of satellitederived $\mathrm{F}$ at specific narrow spectral intervals has already been considered and recognized as a prominent scientific achievement; however, this information still could be insufficient to the biological plant physiology communities wishing to use more comprehensive $\mathrm{F}$ information that will enable a deeper understanding of the mechanisms of energy transfer underlying the photosynthetic process in plant canopies and ecosystems.

Hence, our ability to estimate the spectrally resolved $\mathrm{F}$ signal at any atmospheric level (either airborne or satellite) is, therefore, closely linked to the accuracy achieved on the characterization of the atmospheric state and the resulting light interactions. In the case of proximal sensing scenarios, e.g., using systems mounted on towers with typical target-sensor distances ranging from a few meters to approximately one hundred meters, the principal atmospheric effect to be corrected is the gas absorption mainly associated with the oxygen regions (e.g., $\mathrm{O}_{2}-\mathrm{A}$, $\mathrm{O}_{2}-\mathrm{B}$ ). Since oxygen abundance is pressure-driven, oxygen absorption effects are relatively more significant within the lower layers of the atmosphere. When increasing the target-sensor optical path, a full atmospheric correction scheme is required, such that the accurate estimation of the aerosol load and scattering effects is essential. Despite this being a challenging task, the atmospheric chemistry and aerosol satellite remote sensing scientific communities have decades of experience. This fact, together with increasingly advanced technology and new satellite missions like FLEX, including its tandem mission concept with Sentinel-3, brings new opportunities to derive spectrally resolved $\mathrm{F}$ measures from harmonized TOA synergy data products using different sensor radiances.

Imaging sensor requirements: As already stated, the F flux is rather small (1-2\%) compared to the reflected portion of the radiance, pushing current methods to rely on strong absorption regions where the sensitivity to detect $F$ increases. These absorption regions, either solar or telluric, are spectrally narrow and present contrasting radiance levels inside and outside the absorption feature. These facts pose challenging requirements on the instruments to be suitable for measuring fluorescence (Damm et al. 2011, Pacheco-Labrador et al. 2019):

- High spectral sampling and resolution, less than $0.3 \mathrm{~nm}$ for the wider $\mathrm{O}_{2}$ absorptions or $0.03 \mathrm{~nm}$ for the narrower Fraunhofer lines. Nonetheless, a coarser resolution will still be able to produce $\mathrm{F}$ estimates with reduced accuracy. - High radiometric resolution and dynamic range. Since the fluorescence radiance is very small and overlaps with reflected radiance, it is necessary to measure the full range of radiance levels from very low $\left(\sim 5 \mathrm{~mW} \mathrm{~m}^{-2} \mathrm{~nm}^{-1} \mathrm{sr}^{-1}\right)$ to very high $\left(>300 \mathrm{~mW} \mathrm{~m}^{-2} \mathrm{~nm}^{-1} \mathrm{sr}^{-1}\right)$, while at the same time being able to resolve very small radiance differences (at least $0.2 \mathrm{~mW} \mathrm{~m}^{-2} \mathrm{~nm}^{-1} \mathrm{sr}^{-1}$ of radiometric resolution).

- Low noise level, while performing at low integration time. This is particularly true for sensors that are mounted on moving platforms such as aircrafts or satellites.

But even with high-performance instruments, it is 
necessary to account for unavoidable instrumental distortions before obtaining reliable measurements, particularly for imaging systems. These include:

- Smile and band-broadening. Spectral characteristics might vary with the instrument's temperature, or along with an array of detectors in an imaging system due to nonplanar focal planes (Pacheco-Labrador et al. 2019). - Nonlinear response of the radiometer. Since all the retrieval methods rely on combining low signal bands (inside the absorption) with high signal bands (outside the absorption), nonlinearity would result in a deviation in the proportionality of those signals, which would translate to an increase or decrease of the F estimation (PachecoLabrador et al. 2019).

- Stray light and out-of-band transmission of the spectral response function (SRF) and point spread function (PSF). These effects transfer energy from one spectral band to neighbouring bands, distorting the recorded signal with respect to the actual value. This effect tends to be small and typically discarded in other applications but turns out to be nonnegligible for fluorescence sensing (Alonso et al. 2017, Albert et al. 2019).

Failing to account for all these effects can result in large deviations in the retrieval of fluorescence, either by overor underestimation. This can end up creating situations where one can erroneously produce negative fluorescence from vegetation, or fluorescence from nonfluorescent targets.

Fluorescence-aimed imaging sensors currently operate from aircraft, e.g., HyPlant (Rascher et al. 2015), FIREFLY (Paynter et al. 2020), the Chlorophyll Fluorescence Imaging Spectrometer (CFIS, a NASA sensor, Frankenberg et al. 2018) or will operate from future satellite (FLEXFLORIS) platforms. The FLEX-FLORIS sensor set combines a high resolution (HR) and low resolution (LR) sensor to cover requirements on the fluorescence retrieval on the one hand and the retrieval of specific APAR and NPQ products on the other hand (Table 1). These particularly dedicated fluorescence sensors are further accompanied by full-range VNIR spectrometers in the same platform (e.g., HyPlant airborne system) or concurrently in a separate one (e.g., FLEX-Sentinel-3 tandem mission) to be able to obtain a full characterization of the atmosphere and other biophysical parameters needed for a proper interpretation of the F signal. However, this is not regularly the case for satellites developed for atmospheric chemistry, such as OCO-2\&3, TROPOMI, or GOME-2\&3.

\section{Towards photosynthesis products and global monitoring strategies}

Requirement of additional parameters constraining photosynthesis: The objective of retrieving $\Phi_{\mathrm{F}}$, indicative of the excitation pressure of the photosynthetic antenna, may seem sufficient for the calculation of the ETR under optimal conditions, but this is not the case for environmentally-induced stressful conditions. The relationship between $\Phi_{\mathrm{F}}$ and $\Phi_{\mathrm{P}}$ is known to be variable along the gradient of physiological plant strain (PorcarCastell et al. 2014) imposing a further need to quantify the stress level and physically-based constraints affecting the $\Phi_{\mathrm{F}}-\Phi_{\mathrm{P}}$ relationship. In the common natural case of excessive radiation arriving at the photosynthetic antenna, additional energy sinks are created within the antenna, causing a reallocation excitation energy among different pathways and modified connectivity. The regulated NPQ mechanisms, forming a crucial part in the energy redistribution, remain poorly understood, except for the established role of the xanthophyll molecules in the energy-dependent quenching mechanism (Gilmore and Yamamoto 1993). Additional creations of molecular energy traps, involving the xanthophylls, and possibly affecting the behaviour of Chl $a$ (without changes in $\mathrm{F}$ lifetime), remain unquantified. Recent proximal sensing experiments have demonstrated an interesting cascade of regulated photoprotection mechanisms detected from changes in the spectrally resolved APAR and adjacent range until up to $750 \mathrm{~nm}$ (Van Wittenberghe et al. 2019). These observations of leaves exposed to excessive light indicate detailed spectral behaviour that is commonly (only partially) monitored by single spectral bands such as employing the Photochemical Reflectance Index (i.e., 531 and $570 \mathrm{~nm}$ ), the most common spectral parameter to indicate changes in NPQ. Hence, the quantification of such NPQ molecular traps beyond the use of indices such as PRI, by characterizing specific absorption behaviour and differentiating the relevance of various xanthophylls (Van Wittenberghe et al. 2021), is therefore identified as a further relevant research objective for the FLEX mission. To reach this goal, a very high precision (within $1 \%$ maximum error) of the retrieved 'true' vegetation reflectance is required, especially in the dynamic range of the xanthophyll-related behaviour, also referred to as the PRI region (Table 1). This objective poses strong requirements on the atmospheric correction process and

Table 1. Spectral resolution, spectral sampling interval, and signal-to-noise (SNR) ratio requirements of the FLEX-FLORIS high resolution (HR) and low resolution (LR) sensors at the threshold levels for the reference radiance defined to detect accurate canopy fluorescence and related dynamics for natural vegetation types under an average solar elevation [after Coppo et al. (2017), ESA (2018)].

\begin{tabular}{llllllllll}
\hline & PRI region & Chl absorption & $\mathrm{O}_{2}$-B & \multicolumn{7}{l}{ Red edge } & $\mathrm{O}_{2}$-A \\
\hline Wavelength [nm] & $500-600$ & $600-677$ & $677-686$ & $686-697$ & $697-740$ & $740-755$ & $755-759$ & $759-769$ & $769-780$ \\
FLORIS spectrometer & $\mathrm{LR}$ & $\mathrm{LR}$ & $\mathrm{HR}$ & $\mathrm{HR}$ & $\mathrm{LR}$ & $\mathrm{HR}$ & $\mathrm{HR}$ & $\mathrm{HR}$ & $\mathrm{HR}$ \\
Spectral resolution [nm] & 3 & 3 & 0.6 & 0.3 & 2 & 0.7 & 0.7 & 0.3 & 0.7 \\
Spectral sampling [nm] & 2 & 2 & 0.5 & 0.1 & 0.65 & 0.5 & 0.5 & 0.1 & 0.5 \\
SNR & 245 & 245 & 340 & 175 & 425 & $510-1,015$ & 1,015 & $115-455$ & 1,015 \\
\hline
\end{tabular}


represents a major challenge for retrieving these underlying spectral dynamics from the background reflectance at larger spatial scales (Sabater et al. 2021).

Bottom-up Cal/Val strategies: As demonstrated in the previous sections, linking the canopy or pixel $\mathrm{F}$ flux to the quantitative information resolving the photosynthetic energy partitioning through the retrieval of $\Phi_{\mathrm{F}}$ will require a coherent strategy based on estimating the emission from the original source, i.e., the $\mathrm{Chl} a$ molecules at the photosystems. Overcoming the various signal distortions suffered, from the molecularly-emitted to sensor-retrieved F flux, is the major challenge for remote sensing of fluorescence; these distortions being related to (1) leaf and canopy radiative transfer properties, (2) surface geophysical properties, and (3) attenuation in the atmosphere. The complexity and finesse required for the correction of all these distortions and flux alternations make it indispensable (even more so than for other missions) to perform calibration and validation activities for the retrieved $\mathrm{F}$. Calibration and validation strategies for the sensor-retrieved F should attempt to quantify and verify the utilized retrieval method with the ground truth of the underlying vegetation target. Quantifying the spatial variability of all the involved parameters is of course an impractical goal, even for medium-resolution satellite pixels of $300 \times 300 \mathrm{~m}$, as in the case of FLEX. For this reason, bottom-up strategies are proposed as a reliable and consistent method for the calibration and validation of the retrieved $\mathrm{F}$ from satellite and airborne sensors (Mohammed et al. 2016). The bottom-up approach consists of relating the concurrently retrieved $\mathrm{F}$ fluxes measured over a range of spatial scales, sampling sparsely but more evenly with the finer spectral resolution instruments (placed closer to the ground). Then, each scale is used to validate the previous, from finer to coarser. This strategy can involve measurements that are either direct and punctual [e.g., by leaf-level set-ups allowing a fast-intermittent blocking of the solar (ir)radiance contribution, therefore isolating the $F$ emission] or more indirect and continuous by the sensorretrieved $\mathrm{F}$ from various platforms such as tower, zip-line, unmanned aerial vehicle (UAV), or airborne platforms to efficiently and quickly acquire higher spatial signal heterogeneity (Zarco-Tejada et al. 2012, Wieneke et al. 2016, Aasen et al. 2019, Vargas et al. 2020). Additionally, leaf-level $\mathrm{F}$ measurements might be used to validate and/or constrain TOC measurements and retrieval methods. An important aspect of the $\mathrm{F}$ retrievals, even at proximal distances, remains the compensation of atmospheric effects. Even from several meters of target-sensor distance, atmospheric effects are shown to strongly impact the retrieval results retrieved from proximal sensors, particularly at the $\mathrm{O}_{2}-\mathrm{B}$ and $\mathrm{O}_{2}-\mathrm{A}$ absorption bands if not properly accounted for (Sabater et al. 2018). Cal/Val sites should also deliver any other biophysical parameters needed for the proper interpretation of the F signal in its role in the photosynthetic processes, which should also be validated and evaluated as to their performance and accuracy. Targeted mission products, such as the $\Phi_{\mathrm{F}}$ and
PSI-PSII F decoupling that is necessary to provide the ETR or instantaneous photosynthesis, will require further validation strategies to assess the dynamic variability of these parameters.

Higher-level data processing towards GPP: Although the relationship between $F$ (as a scalar related to energy released at either peak of emission, or to a lesser extent, the integrated emission) and photosynthesis or GPP may have been shown as linearly related from global satellite imaging derived from pixels at very large spatial scales, i.e., at $40 \times 80 \mathrm{~km}^{2}$ (GOME-2) (Guanter et al. 2014, Joiner et al. 2016), $7 \times 7 \mathrm{~km}^{2}$ (TROPOMI) (Philipp et al. 2018), $10 \times 10 \mathrm{~km}^{2}($ GOSAT) (Sun et al. 2018), the quantitative link between the $\mathrm{F}$ emission and the actual carbon sequestration currently remains biased due to the many effects described in the previous sections. Large-footprint sensors also come with the difficulty of being easily affected by clouds and pixel heterogeneity, complicating the quantitative interpretation of surface-dependent flux parameters such as F. With FLEX, a higher spatial resolution will be possible globally, but observations will be less frequent, challenging the temporal assessment of stress-related photosynthetic constraints. With a revisit time of $27 \mathrm{~d}$ at the equator and $\leq 6 \mathrm{~d}$ above the polar circle, the boreal forests will be more frequently revisited, allowing a better temporal assessment of seasonal photosynthetic activation, where greenness indicators remain relatively constant during the whole year. Despite the long revisit time, FLEX can bring, based on the very complete spectral coverage and targeted products, opportunities to assess the quantum efficiencies of the processes within the light reactions. With the aimed development and delivery of the actual ETR, the coupling between light and dark reactions needs to be addressed and perhaps requires rethinking. Here, the retrieval of PSI and PSII F contributions (Fig. 4), considering further complex signal variations, plays a crucial part in the FLEX strategy for the retrieval of the actual electron transport rate. Where traditionally satellite-based GPP models have used the Farquhar-von Caemmerer-Berry biochemical photosynthesis model to parametrize to a larger extent the dark reactions, FLEX aims to provide light-reaction-centric input for the full biophysical model of photosynthesis. Only after further data processing and including a suitable biochemical model for $\mathrm{C}_{3}$ and $\mathrm{C}_{4}$ vegetation types to derive instantaneous photosynthesis, combined with data assimilation based on a more in-depth understanding of the dynamical relationships of the instantaneous products, can an advanced strategy to assess GPP at global scale be crystalized (Fig. 10, Table 2).

Conclusions: Since the initial work of Hartmut Lichtenthaler and his colleagues on vegetation fluorescence imaging at leaf level using small lamps, eventually leading to the capability of global mapping of vegetation fluorescence over the whole Earth surface using the Sun as a big lamp, numerous steps have been taken both on the technology and scientific sides, many of which are part of the preparatory activities of the FLEX mission over the 


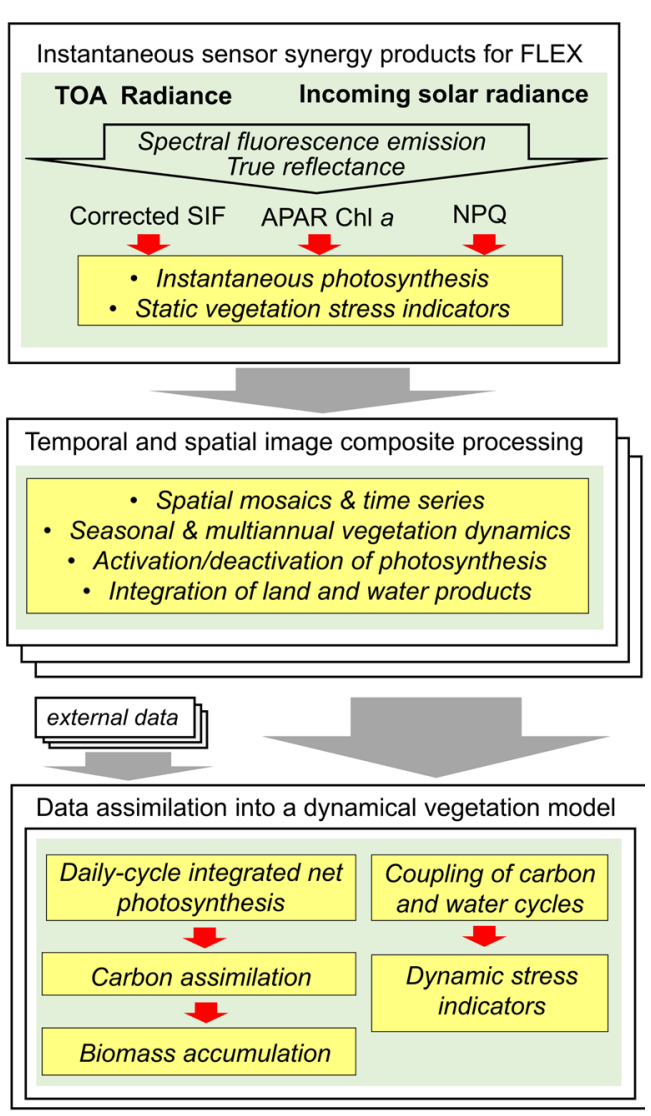

Fig. 10. A schematic overview of the data processing of single FLEX images to derive dynamic photosynthesis products to be incorporated into an advanced data assimilation scheme, providing higher-level spatial and temporal composite products such as GPP and dynamic stress indicators. last 20 years. Without such pioneering work in the early $1990 \mathrm{~s}$, the current understanding of the fluorescence signal and the capability for mapping large areas using 'imaging' techniques would have not been possible.

Thanks to emerging techniques in fluorescence imaging spectroscopy, both technological and methodological, highly valuable opportunities for novel quantitative vegetation monitoring are rising for the retrieval of spectrally-resolved vegetation fluorescence $(650-800 \mathrm{~nm})$, an energy flux directly emitted from the active photosynthetic elements of vegetation. Among the stringent technological instrument requirements are an ultra-high spectral resolution, a high dynamic range, a fine radiometric resolution, and a higher-than-average signal-to-noise ratio. Further, the methodology requires unprecedented atmospheric correction accuracies, and retrieval algorithms capable of disentangling the $\mathrm{F}$ signal from the reflected radiance while coping with a number of distortions to the first-order Chl $a$ molecular emission. These distortions are either smooth, due to the absorption behaviour of Chl $a$ itself, or discrete at particular wavelengths, due to interaction with specific molecules and aerosols encountered along the optical path. Without dealing with any of these, any attempt to estimate fluorescence will translate into inaccurate or biased results and complicate its use as a quantitative proxy of the physiological antenna state and the estimation of actual photosynthesis. To resolve the actual quantum efficiencies at any imaging scale, the requirement of a high-precision true reflectance instrument (500-780 $\mathrm{nm}$ ) accompanying the fluorescence spectral information is thereby crucial for the retrieval of (1) the absorbed energy flux driving the emission, and (2) the nonphotochemical quenching levels. Careful validation strategies by multi-scale field measurements using well-calibrated instruments and accurate signal

Table 2. List of FLEX strategic quantities for global vegetation monitoring through different levels of data processing.

\begin{tabular}{|c|c|c|}
\hline Data processing stage & Product & Specifics and comments \\
\hline \multirow[t]{6}{*}{$\begin{array}{l}\text { Instantaneous sensor } \\
\text { synergy products }\end{array}$} & Total 'true' fluorescence emission & $\begin{array}{l}\text { Spectrally integrated values at canopy level at } 300 \mathrm{~m} \text { original } \\
\text { spatial resolution, corrected for reabsorption and scattering effects }\end{array}$ \\
\hline & PSI-PSII fluorescence contributions & $\begin{array}{l}\text { Contributions of the two photosystem's fluorescence emission, } \\
\text { indicative for their respective antenna sizes }\end{array}$ \\
\hline & Nonphotochemical energy dissipation & $\begin{array}{l}\text { Regulated energy dissipation, accounts for the fraction of light } \\
\text { absorbed by nonphotochemical pigments }\end{array}$ \\
\hline & Fluorescence quantum efficiency & $\begin{array}{l}\text { The ratio between the photons emitted as fluorescence versus } \\
\text { actual chlorophyll specific absorption }\end{array}$ \\
\hline & Photosynthesis rate & $\begin{array}{l}\text { Effective charge separation at PSII interpreted as actual electron } \\
\text { transport rate }\end{array}$ \\
\hline & Vegetation stress & Defined as 'actual photosynthesis/potential photosynthesis' \\
\hline \multirow{3}{*}{$\begin{array}{l}\text { Composite-derived } \\
\text { products }\end{array}$} & Spatial mosaics & Regional/continental/global maps \\
\hline & Temporal composites & Monthly/seasonal/annual composites \\
\hline & Activation/deactivation of photosynthesis & Determines the length of the growing season for ecosystems \\
\hline \multirow[t]{2}{*}{$\begin{array}{l}\text { Data assimilation } \\
\text { products }\end{array}$} & Gross primary productivity (GPP) & $\begin{array}{l}\text { Carbon uptake, derived by data assimilation with the usage of } \\
\text { external inputs from meteorological data and land cover maps }\end{array}$ \\
\hline & Dynamical vegetation stress & $\begin{array}{l}\text { Decoupling between different stresses through dynamical } \\
\text { vegetation processes modelling }\end{array}$ \\
\hline
\end{tabular}


processing will be further indispensable to ensure the accuracy of the retrieved $\mathrm{F}$ and supporting parameters. The integral use of series of these instantaneously obtained photosynthesis-related products, in combination with advanced data processing, will trigger quantitative knowledge on both the actual and potential photosynthetic status in space and time at larger spatial scales as measured by global imaging systems.

\section{References}

Aasen H., Van Wittenberghe S., Sabater N.S. et al.: Sun-induced chlorophyll fluorescence II: Review of passive measurement setups, protocols, and their application at the leaf to canopy level. - Remote Sens.-Basel 11: 927, 2019.

Agati G., Fusi F., Mazzinghi P., di Paola M.L.: A simple approach to the evaluation of the reabsorption of chlorophyll fluorescence spectra in intact leaves. - J. Photoch. Photobio. B 17: 163-171, 1993.

Akoumianaki-Ioannidou A., Georgakopoulos J.H., Fasseas C., Argyroudi-Akoyunoglou J.H.: Photoacclimation in Spathiphyllum. - J. Photoch. Photobio. B 73: 149-158, 2004.

Albert L.P., Cushman K.C., Allen D.W. et al.: Stray light characterization in a high-resolution imaging spectrometer designed for solar-induced fluorescence. - In: Velez-Reyes M., Messinger D.W. (ed.): Proc. SPIE 10986. Algorithms, Technologies, and Applications for Multispectral and Hyperspectral Imagery XXV, 2019.

Alonso L., Gomez-Chova L., Vila-Francés J. et al.: Improved Fraunhofer line discrimination method for vegetation fluorescence quantification. - IEEE Geosci. Remote Sens. Lett. 5: 620-624, 2008.

Alonso L., Moreno J.: A novel portable device to measure leaf reflectance, transmittance, and fluorescence emission under natural conditions. - In: Proceedings of the $4^{\text {th }}$ International Workshop on Remote Sensing of Vegetation Fluorescence, Valencia, Spain. Pp. 1-17. 2010.

Alonso L., Vicent J., Sabater N. et al.: Impact of instrument characterization in the retrieval of SIF: HyPlant case study. In: Remote Sensing of Fluorescence, Photosynthesis and Vegetation Status. ESA-ESRIN, Frascati 2017.

Amorós-López J., Gomez-Chova L., Vila-Frances J. et al.: Study of the diurnal cycle of stressed vegetation for the improvement of fluorescence remote sensing. - In: Proc. SPIE 6359, Remote Sensing for Agriculture, Ecosystems, and Hydrology VIII. SPIE, 2006.

Berk A., Anderson G.P., Acharya P.K. et al:: MODTRAN 5: a reformulated atmospheric band model with auxiliary species and practical multiple scattering options: update. - In: Proc. SPIE 5806, Algorithms and Technologies for Multispectral, Hyperspectral, and Ultraspectral Imagery XI. Pp. 662-667. SPIE, 2005.

Bilger W., Björkman O.: Role of the xanthophyll cycle in photoprotection elucidated by measurements of light-induced absorbance changes, fluorescence and photosynthesis in leaves of Hedera canariensis. - Photosynth. Res. 25: 173185, 1990.

Biriukova K., Celesti M., Evdokimov A. et al.: Effects of varying solar-view geometry and canopy structure on solar-induced chlorophyll fluorescence and PRI. - Int. J. Appl. Earth Obs. Geoinf. 89: 102069, 2020.

Björkman O., Demmig B.: Photon yield of $\mathrm{O}_{2}$ evolution and chlorophyll fluorescence characteristics at $77 \mathrm{~K}$ among vascular plants of diverse origins. - Planta 170: 489-504, 1987.
Björn L.O., Papageorgiou G.C., Blankenship R.E., Govindjee: A viewpoint: Why chlorophyll $a$ ? - Photosynth. Res. 99: 8598, 2009.

Buschmann C.: Variability and application of the chlorophyll fluorescence emission ratio red/far-red of leaves. - Photosynth. Res. 92: 261-271, 2007.

Campbell P.K.E., Huemmrich K.F., Middleton E.M. et al.: Diurnal and seasonal variations in chlorophyll fluorescence associated with photosynthesis at leaf and canopy scales. Remote Sens.-Basel 11: 488, 2019.

Cendrero-Mateo M.P., Wieneke S., Damm A. et al.: Sun-induced chlorophyll fluorescence III: Benchmarking retrieval methods and sensor characteristics for proximal sensing. - Remote Sens.-Basel 11: 962, 2019.

Chang C.Y., Guanter L., Frankenberg C. et al.: Systematic assessment of retrieval methods for canopy far-red solarinduced chlorophyll fluorescence using high-frequency automated field spectroscopy. - J. Geophys. Res.-Biogeo. 125: e2019JG005533, 2020.

Chow W.S., Melis A., Anderson J.M.: Adjustments of photosystem stoichiometry in chloroplasts improve the quantum efficiency of photosynthesis. - P. Natl. Acad. Sci. USA 87: 7502-7506, 1990.

Cogliati S., Celesti M., Cesana I. et al:: A spectral fitting algorithm to retrieve the fluorescence spectrum from canopy radiance. - Remote Sens.-Basel 11: 1840, 2019.

Cogliati S., Verhoef W., Kraft S. et al.: Retrieval of sun-induced fluorescence using advanced spectral fitting methods. Remote Sens. Environ. 169: 344-357, 2015.

Coppo P., Taiti A., Pettinato L. et al.: Fluorescence imaging spectrometer (FLORIS) for ESA FLEX mission. - Remote Sens.-Basel 9: 649, 2017.

Crisp D., Pollock H.R., Rosenberg R. et al.: The on-orbit performance of the Orbiting Carbon Observatory-2 (OCO-2) instrument and its radiometrically calibrated products. Atmos. Meas. Tech. 10: 59-81, 2017.

Croce R., Dorra D., Holzwarth A.R., Jennings R.C.: Fluorescence decay and spectral evolution in intact Photosystem I of higher plants. - Biochemistry-US 39: 6341-6348, 2000.

Damm A., Elber J., Erler A. et al.: Remote sensing of suninduced fluorescence to improve modeling of diurnal courses of gross primary production (GPP). - Glob. Change Biol. 16: 171-186, 2010.

Damm A., Erler A., Hillen W. et al.: Modeling the impact of spectral sensor configurations on the FLD retrieval accuracy of sun-induced chlorophyll fluorescence. - Remote Sens. Environ. 115: 1882-1892, 2011.

Daumard F., Champagne S., Fournier A. et al.: A field platform for continuous measurement of canopy fluorescence. - IEEE Trans. Geosci. Remote Sens. 48: 3358-3368, 2010.

Demmig-Adams B.: Carotenoids and photoprotection in plants: A role for the xanthophyll zeaxanthin. - BBA-Bioenergetics 1020: 1-24, 1990.

Demmig-Adams B., Stewart J.J., López-Pozo M. et al.: Zeaxanthin, a molecule for photoprotection in many different environments. - Molecules 25: 5825, 2020.

Diedrich H., Preusker R., Lindstrot R., Fischer J.: Retrieval of daytime total columnar water vapor from MODIS measurements over land surfaces. - Atmos. Meas. Tech. 8: 823-836, 2015.

Doornink J., de Vries J., Voors R. et al.: The Tropomi instrument: last steps towards final integration and testing. - In: Proc. SPIE 10563, International Conference on Space Optics, Tenerife 2014. ICSO, 2014.

Drusch M., Moreno J., Del Bello U. et al.: The FLuorescence EXplorer Mission Concept - ESA's Earth Explorer 8. - IEEE 
Trans. Geosci. Remote Sens. 55: 1273-1284, 2017.

Du S., Liu L., Liu X., Hu J.: Response of canopy solar-induced chlorophyll fluorescence to the absorbed photosynthetically active radiation absorbed by chlorophyll. - Remote Sens.Basel 9: 911, 2017.

Emde C., Buras-Schnell R., Kylling A. et al.: The libRadtran software package for radiative transfer calculations version 2.0.1. - Geosci. Model Dev. 9: 1647-1672, 2016.

ESA (European Space Agency): FLEX Earth Explorer 8 Mission Requirements Document, Version 3.0, Issue Date 05/06/2018, ESA Earth and Mission Science Division, Ref: ESAEOPSM/2221/MDru-md, 2018.

Fischer J., Leinweber R., Preusker R.: Retrieval of total water vapour content from MERIS measurements. Algorithm theoretical basis document ATBD 2.4. Pp. 23. Free University of Berlin, Institute for Space Science, Berlin 2010.

Fournier A., Daumard F., Champagne S. et al.: Effect of canopy structure on sun-induced chlorophyll fluorescence. - ISPRS J. Photogramm. Remote Sens. 68: 112-120, 2012.

Franck F., Juneau P., Popovic R.: Resolution of the Photosystem I and Photosystem II contributions to chlorophyll fluorescence of intact leaves at room temperature. - BBA-Bioenergetics 1556: 239-246, 2002.

Frank H.A., Young A.J., Britton G., Cogdell R.J.: The Photochemistry of Carotenoids. Advances in Photosynthesis and Respiration. Pp. 401. Springer, Dordrecht 1999.

Frankenberg C., Berry J.: Solar induced chlorophyll fluorescence: origins, relation to photosynthesis and retrieval. - In: Liang S. (ed.): Comprehensive Remote Sensing. Pp. 143-162. Elsevier, 2018.

Frankenberg C., Köhler P., Magney T.S. et al.: The Chlorophyll Fluorescence Imaging Spectrometer (CFIS), mapping far red fluorescence from aircraft. - Remote Sens. Environ. 217: 523536, 2018.

Frankenberg C., O'Dell C., Berry J. et al.: Prospects for chlorophyll fluorescence remote sensing from the Orbiting Carbon Observatory-2. - Remote Sens. Environ. 147: 1-12, 2014.

Gastellu-Etchegorry J.P., Grau E., Lauret N.: DART: A 3D Model for Remote Sensing Images and Radiative Budget of Earth Surfaces. - In: Alexandru C. (ed.): Modeling and Simulation in Engineering. Pp. 29-68. InTech, 2012.

Gilmore A.M., Yamamoto, H.Y.: Linear models relating xanthophylls and lumen acidity to non-photochemical fluorescence quenching. Evidence that antheraxanthin explains zeaxanthinindependent quenching. - Photosynth. Res 35: 67-78, 1993.

Gitelson A.A., Buschmann C., Lichtenthaler H.K.: Leaf chlorophyll fluorescence corrected for re-absorption by means of absorption and reflectance measurements. - J. Plant Physiol. 152: 283-296, 1998.

Gitelson A.A., Gamon J.A.: The need for a common basis for defining light-use efficiency: Implications for productivity estimation. - Remote Sens. Environ. 156: 196-201, 2015.

Glumb R., Davis G., Lietzke C.: The TANSO-FTS-2 instrument for the GOSAT-2 greenhouse gas monitoring mission. In: IEEE Geoscience and Remote Sensing Symposium, Quebec City 2014. IEEE, 2014.

Goulas Y., Fournier A., Daumard F. et al.: Gross primary production of a wheat canopy relates stronger to far red than to red solar-induced chlorophyll fluorescence. - Remote Sens.-Basel 9: 97, 2017.

Guanter L., Frankenberg C., Dudhia A. et al.: Retrieval and global assessment of terrestrial chlorophyll fluorescence from GOSAT space measurements. - Remote Sens. Environ. 121: 236-251, 2012.

Guanter L., Zhang Y., Jung M. et al.: Global and time-resolved monitoring of crop photosynthesis with chlorophyll fluorescence. - P. Natl. Acad. Sci. USA 111: E1327-E1333, 2014.

Haboudane D., Miller J.R., Pattey E. et al.: Hyperspectral vegetation indices and novel algorithms for predicting green LAI of crop canopies: Modeling and validation in the context of precision agriculture. - Remote Sens. Environ. 90: 337$352,2004$.

He L., Chen J.M.C., Liu J. et al.: Angular normalization of GOME-2 sun-induced chlorophyll fluorescence observation as a better proxy of vegetation productivity. - Geophys. Res. Lett. 44: 5691-5699, 2017.

Hernández-Clemente R., North P.R.J., Hornero A., ZarcoTejada P.J.: Assessing the effects of forest health on suninduced chlorophyll fluorescence using the FluorFLIGHT 3-D radiative transfer model to account for forest structure. Remote Sens. Environ. 193: 165-179, 2017.

Hill C., Gordon I.E., Kochanov R.V. et al.: HITRANonline: An online interface and the flexible representation of spectroscopic data in the HITRAN database. - J. Quant. Spectrosc. Ra. 177: 4-14, 2016.

Jahns P., Holzwarth A.R.: The role of the xanthophyll cycle and of lutein in photoprotection of photosystem II. BBA-Bioenergetics 1817: 182-193, 2012.

Joiner J., Yoshida Y., Guanter L. et al.: New methods for retrieval of chlorophyll red fluorescence from hyper-spectral satellite instruments: simulations and application to GOME-2 and SCIAMACHY. - Atmos. Meas. Tech. 9: 3939-3967, 2016.

Joiner J., Yoshida Y., Vasilkov A.P. et al.: First observations of global and seasonal terrestrial chlorophyll fluorescence from space. - Biogeosciences 8: 637-651, 2011.

Kiang N.Y., Siefert J., Govindjee, Blankenship R.E.: Spectral signatures of photosynthesis. I. Review of Earth organisms. Astrobiology 7: 222-251, 2007.

Kopp G., Lean J.L.: A new, lower value of total solar irradiance: Evidence and climate significance. - Geophys. Res. Lett. 38: L01706, 2011.

Krüger T.P.J., van Grondelle R.: The role of energy losses in photosynthetic light harvesting. - J. Phys. B: At. Mol. Opt. Phys. 50: 132001, 2017.

Lambrev P.H., Miloslavina Y., Jahns P., Holzwarth A.R.: On the relationship between non-photochemical quenching and photoprotection of Photosystem II. - BBA-Bioenergetics 1817: 760-769, 2012.

Lambrev P.H., Nilkens M., Miloslavina Y. et al.: Kinetic and spectral resolution of multiple nonphotochemical quenching components in Arabidopsis leaves. - Plant Physiol. 152: 1611-1624, 2010.

Leuenberger M., Morris J.M., Chan A.M. et al.: Dissecting and modelling zeaxanthin- and lutein-dependent nonphotochemical quenching in Arabidopsis thaliana. - P. Natl. Acad. Sci. USA 114: E7009-E7017, 2017.

Liang S., Wang J.: Fractional vegetation cover. - In: Liang S., Wang J. (ed.): Advanced Remote Sensing: Terrestrial Information Extraction and Applications. Pp. 477-510. Academic Press, London 2020.

Lichtenthaler H.K., Langsdorf G., Lenk S., Buschmann C.: Chlorophyll fluorescence imaging of photosynthetic activity with the flash-lamp fluorescence imaging system. Photosynthetica 43: 355-369, 2005.

Lichtenthaler H.K., Miehé J.A.: Fluorescence imaging as a diagnostic tool for plant stress. - Trends Plant Sci. 2: 316320, 1997.

Lichtenthaler H.K., Wenzel O., Buschmann C., Gitelson A.: Plant stress detection by reflectance and fluorescence. - Ann. N. Y. Acad. Sci. 851: 271-285, 1998.

Liu X., Guanter L., Liu L. et al.: Downscaling of solar-induced 
chlorophyll fluorescence from canopy level to photosystem level using a random forest model. - Remote Sens. Environ. 231: 110772, 2019.

Long D.A., Hodges J.T.: On spectroscopic models of the $\mathrm{O}_{2}$ $A$-band and their impact upon atmospheric retrievals. J. Geophys. Res. Atmos. 117: D12309, 2012.

Louis J., Cerovic Z.G., Moya I.: Quantitative study of fluorescence excitation and emission spectra of bean leaves. - J. Photoch. Photobio. B 85: 65-71, 2006.

Louis J., Ounis A., Ducruet J.-M. et al:: Remote sensing of sunlight-induced chlorophyll fluorescence and reflectance of Scots pine in the boreal forest during spring recovery. Remote Sens. Environ. 96: 37-48, 2005.

MacBean N., Maignan F., Bacour C. et al.: Strong constraint on modelled global carbon uptake using solar-induced chlorophyll fluorescence data. - Sci. Rep.-UK 8: 1973, 2018.

Magney T.S., Frankenberg C., Köhler P. et al.: Disentangling changes in the spectral shape of chlorophyll fluorescence: Implications for remote sensing of photosynthesis. J. Geophys. Res.-Biogeo. 124: 1491-1507, 2019.

Maier S.W., Günther K.P., Stellmes M.: Sun-induced fluorescence: A new tool for precision farming. - In: VanToai T., Major D., McDonald M. et al. (ed.): Digital Imaging and Spectral Techniques: Applications to Precision Agriculture and Crop Physiology. Vol. 66. Pp. 207-222. American Society of Agronomy, Crop Science Society of America, Soil Science Society of America, Madison 2004.

Meroni M., Busetto L., Colombo R. et al.: Performance of Spectral Fitting Methods for vegetation fluorescence quantification. Remote Sens. Environ. 114: 363-374, 2010.

Meroni M., Colombo R.: Leaf level detection of solar induced chlorophyll fluorescence by means of a subnanometer resolution spectroradiometer. - Remote Sens. Environ. 103: 438-448, 2006.

Meroni M., Rossini M., Guanter L. et al.: Remote sensing of solar-induced chlorophyll fluorescence: Review of methods and applications. - Remote Sens. Environ. 113: 2037-2051, 2009.

Miloslavina Y., Wehner A., Lambrev P.H. et al.: Far-red fluorescence: A direct spectroscopic marker for LHCII oligomer formation in non-photochemical quenching. - FEBS Lett. 582: 3625-3631, 2008.

Mohammed G.H., Colombo R., Middleton E.M. et al.: Remote sensing of solar-induced chlorophyll fluorescence (SIF) in vegetation: 50 years of progress. - Remote Sens. Environ. 231: 111177, 2019.

Mohammed G.H., Colombo R., Moreno J. et al:: FLEX Bridge Study, Final Report ESA/ESTEC Contract No. 4000112341/14/ NL/FF/gp. Pp. 192. P \& M Technologies, 2016.

Moncholí A., Alonso L., Van Wittenberghe S. et al.: Canopy architectural influence on the interpretation of the biophysical parameters and sun-induced chlorophyll fluorescence variability: A small-scale laboratory experiment. - In: $7^{\text {th }}$ International Workshop on Remote Sensing of Vegetation Fluorescence, Davos 2019.

Morcillo-Pallarés P.: A systematic assessment of different fluorescence retrieval methods in the context of the FLEX mission. Master thesis. University of Valencia, Valencia 2020.

Moreno J.F., Asner G.P., Bach H. et al.: Fluorescence explorer (FLEX): An optimised payload to map vegetation photosynthesis from space. - In: AIAA 57 ${ }^{\text {th }}$ International Astronautical Congress, Valencia 2006. Pp. 2065-2074. IAC, 2006.

Moreno J.F., Goulas Y., Huth A. et al.: Very high spectral resolution imaging spectroscopy: The Fluorescence Explorer
(FLEX) mission. - In: 2016 IEEE International Geoscience and Remote Sensing Symposium (IGARSS). Pp. 264-267. IEEE, 2016.

Munro R., Lang R., Klaes D. et al.: The GOME-2 instrument on the Metop series of satellite : instrument design, calibration, and level 1 data processing - an overview. - Atmos. Meas. Tech. 9: 1279-1301, 2016.

Murchie E.H., Horton P.: Acclimation of photosynthesis to irradiance and spectral quality in British plant species: chlorophyll content, photosynthetic capacity and habitat preference. - Plant Cell Environ. 20: 438-448, 1997.

Naumann A.K., Kiemle C.: The vertical structure and spatial variability of lower tropospheric water vapor and clouds in the trades. - Atmos. Chem. Phys. 20: 6129-6145, 2020.

Nematov S., Casazza A.P., Remelli W. et al.: Spectral dependence of irreversible light-induced fluorescence quenching: Chlorophyll forms with maximal emission at 700-702 and $705-710 \mathrm{~nm}$ as spectroscopic markers of conformational changes in the core complex. - BBA-Bioenergetics 1858: 529-543, 2017.

Niinemets Ü., Anten N.P.R.: Packing the photosynthetic machinery: From leaf to canopy. - In: Laisk A., Nedbal L., Govindjee (ed.): Photosynthesis in silico. Advances in Photosynthesis and Respiration. Vol. 29. Pp. 363-399. Springer, Dordrecht 2009.

Pacheco-Labrador J., Hueni A., Mihai L. et al.: Sun-induced chlorophyll fluorescence I : Instrumental Considerations for proximal spectroradiometers. - Remote Sens.-Basel 11: 960, 2019.

Paynter I., Cook B., Corp L. et al.: Characterization of FIREFLY, an imaging spectrometer designed for remote sensing of solar induced fluorescence. - Sensors-Basel 20: 4682, 2020.

Pedrós R., Goulas Y., Jacquemoud S. et al:: FluorMODleaf: A new leaf fluorescence emission model based on the PROSPECT model. - Remote Sens. Environ. 114: 155-167, 2010.

Pedrós R., Moya I., Goulas Y., Jacquemoud S.: Chlorophyll fluorescence emission spectrum inside a leaf. - Photoch. Photobio. Sci. 7: 498-502, 2008.

Petty G.W.: A First Course in Atmospheric Radiation. $2^{\text {nd }}$ Edition. Pp. 472. Sundog Publishing, Madison 2006.

Philipp K., Frankenberg C., Magney T.S. et al.: Global retrievals of solar-induced chlorophyll fluorescence with TROPOMI: First results and intersensor comparison to OCO-2.-Geophys. Res. Lett. 45: 10456-10463, 2018.

Pinto F., Müller-Linow M., Schickling A. et al.: Multiangular observation of canopy sun-induced chlorophyll fluorescence by combining imaging spectroscopy and stereoscopy. Remote Sens.-Basel 9: 415, 2017.

Plascyk J.A.: The MK II Fraunhofer Line Discriminator (FLD-II) for airborne and orbital remote sensing of solar-stimulated luminescence. - Opt. Eng. 14: 144339, 1975.

Porcar-Castell A., Tyystjärvi E., Atherton J. et al.: Linking chlorophyll $a$ fluorescence to photosynthesis for remote sensing applications: Mechanisms and challenges. - J. Exp. Bot. 65: 4065-4095, 2014.

Rascher U., Alonso L., Burkart A. et al.: Sun-induced fluorescence - a new probe of photosynthesis: First maps from the imaging spectrometer HyPlant. - Glob. Change Biol. 21: 4673-4684, 2015.

Roelofs T.A., Lee C.-H., Holzwarth A.R.: Global target analysis of picosecond chlorophyll fluorescence kinetics from pea chloroplasts: A new approach to the characterization of the primary processes in photosystem II $\alpha$ - and $\beta$-units. Biophys. J. 61: 1147-1163, 1992.

Romero J.M., Cordon G.B., Lagorio M.G.: Modeling re- 
absorption of fluorescence from the leaf to the canopy level. Remote Sens. Environ. 204: 138-146, 2018.

Romero J.M., Cordon G.B., Lagorio M.G.: Re-absorption and scattering of chlorophyll fluorescence in canopies: A revised approach. - Remote Sens. Environ. 246: 111860, 2020.

Rossini M., Meroni M., Celesti M. et al.: Analysis of red and far-red sun-induced chlorophyll fluorescence and their ratio in different canopies based on observed and modeled data. Remote Sens.-Basel 8: 412, 2016.

Sabater N., Kolmonen P., Van Wittenberghe S. et al.: Challenges in the atmospheric characterization for the retrieval of spectrally resolved fluorescence and PRI region dynamics from space. - Remote Sens. Environ. 254: 112226, 2021.

Sabater N., Vicent J., Alonso L. et al.: Compensation of oxygen transmittance effects for proximal sensing retrieval of canopyleaving sun-induced chlorophyll fluorescence. - Remote Sens.-Basel 10: 1551, 2018.

Shikanai T.: Cyclic electron transport around photosystem I: genetic approaches. - Annu. Rev. Plant Biol. 58: 199-217, 2007.

Siegmann B., Alonso L., Celesti M. et al.: The high-performance airborne imaging spectrometer HyPlant - From raw images to top-of-canopy reflectance and fluorescence products: Introduction of an automatized processing chain. - Remote Sens.-Basel 11: 2760, 2019.

Stoll M.-P., Buschmann C., Court A. et al: The FLEXFluorescence Explorer mission project: motivations and present status of preparatory activities. - In: IEEE International Geoscience and Remote Sensing Symposium Proceedings. Pp. 585-587. IEEE, 2003.

Stoll M.-P., Laurila T., Cunin B. et al.: FLEX: fluorescence explorer - a space mission for screening vegetated areas in the Fraunhofer lines. - In: SPIE Proceedings 3868, Remote Sensing for Earth Science, Ocean, and Sea Ice Applications, 1999.

Sun Y., Frankenberg C., Jung M. et al.: Overview of solarinduced chlorophyll fluorescence (SIF) from the Orbiting Carbon Observatory-2: Retrieval, cross-mission comparison, and global monitoring for GPP. - Remote Sens. Environ. 209: 808-823, 2018.

Sun Y., Frankenberg C., Wood J.D. et al:: OCO-2 advances photosynthesis observation from space via solar-induced chlorophyll fluorescence. - Science 358: 189, 2017.

Tagliabue G., Panigada C., Celesti M. et al.: Sun-induced fluorescence heterogeneity as a measure of functional diversity. - Remote Sens. Environ. 247: 111934, 2020.

Tenjo C., Rivera-Caicedo J.P., Sabater N. et al:: Design of a Generic 3-D Scene Generator for Passive Optical Missions and Its Implementation for the ESA's FLEX/Sentinel-3 Tandem Mission. - IEEE Trans. Geosci. Remote Sens. 56: 1290-1307, 2018.

van der Tol C., Verhoef W., Timmermans J. et al.: An integrated model of soil-canopy spectral radiances, photosynthesis, fluorescence, temperature and energy balance. Biogeosciences 6: 3109-3129, 2009.

van der Tol C., Vilfan N., Dauwe D. et al.: The scattering and reabsorption of red and near-infrared chlorophyll fluorescence in the models Fluspect and SCOPE. - Remote Sens. Environ. 232: 111292, 2019.

Van Wittenberghe S., Alonso L., Malenovský Z., Moreno J.: In vivo photoprotection mechanisms observed from leaf spectral absorbance changes showing VIS-NIR slow-induced conformational pigment bed changes. - Photosynth. Res. 142: 283-305, 2019.

Van Wittenberghe S., Alonso L., Verrelst J. et al.: Upward and downward solar-induced chlorophyll fluorescence yield indices of four tree species as indicators of traffic pollution in Valencia. - Environ. Pollut. 173: 29-37, 2013.

Van Wittenberghe S., Alonso L., Verrelst J. et al.: Bidirectional sun-induced chlorophyll fluorescence emission is influenced by leaf structure and light scattering properties - A bottom-up approach. - Remote Sens. Environ. 158: 169-179, 2015.

Van Wittenberghe S., Laparra V., García-Plazaola J.I. et al.: Combined dynamics of the 500-600 nm leaf absorption and chlorophyll fluorescence changes in vivo: Evidence for the multifunctional energy quenching role of xanthophylls. BBA-Bioenergetics 1862: 148351, 2021.

Vargas J.Q., Bendig J., MacArthur A. et al.: Unmanned aerial systems (UAS)-based methods for solar induced chlorophyll fluorescence (SIF) retrieval with non-imaging spectrometers: State of the art. - Remote Sens.-Basel 12: 1624, 2020.

Vasilkov A., Joiner J., Spurr R.: Note on rotational-Raman scattering in the $\mathrm{O}_{2}$-A-and B-bands. - Atmos. Meas. Tech. 6: 981-990, 2013.

Verma M., Schimel D., Evans B. et al.: Effect of environmental conditions on the relationship between solar-induced fluorescence and gross primary productivity at an OzFlux grassland site. - J. Geophys. Res.-Biogeo. 122: 716-733, 2017.

Verrelst J., Rivera J.P., van der Tol C. et al.: Global sensitivity analysis of the SCOPE model: What drives simulated canopyleaving sun-induced fluorescence? - Remote Sens. Environ. 166: 8-21, 2015.

Vicent J., Sabater N., Tenjo C. et al.: FLEX end-to-end mission performance simulator. - IEEE Trans. Geosci. Remote Sens. 54: 4215-4223, 2016.

Vicent J., Sabater N., Verrelst J. et al.: Assessment of approximations in aerosol optical properties and vertical distribution into FLEX atmospherically-corrected surface reflectance and retrieved sun-induced fluorescence. - Remote Sens.-Basel 9: 675, 2017.

Wieneke S., Ahrends H., Damm A. et al: Airborne based spectroscopy of red and far-red sun-induced chlorophyll fluorescence: Implications for improved estimates of gross primary productivity. - Remote Sens. Environ. 184: 654-667, 2016.

Yang P., van der Tol C.: Linking canopy scattering of far-red suninduced chlorophyll fluorescence with reflectance. - Remote Sens. Environ. 209: 456-467, 2018.

Yang P., van der Tol C., Campbell P.K.E., Middleton E.M.: Fluorescence Correction Vegetation Index (FCVI): A physically based reflectance index to separate physiological and non-physiological information in far-red sun-induced chlorophyll fluorescence. - Remote Sens. Environ. 240: 111676, 2020.

Zarco-Tejada P.J., González-Dugo V., Berni J.A.J.: Fluorescence, temperature and narrow-band indices acquired from a UAV platform for water stress detection using a micro-hyperspectral imager and a thermal camera. - Remote Sens. Environ. 117: 322-337, 2012.

Zhang Q., Cheng Y.-B., Lyapustin A.I. et al.: Estimation of crop gross primary production (GPP): fAPAR chl $_{\text {versus MOD15A2 }}$ FPAR. - Remote Sens. Environ. 153: 1-6, 2014. 